\title{
Reaching the last mile: main challenges relating to and recommendations to accelerate onchocerciasis elimination in Africa
}

\author{
Gebremedhin Gebrezgabiher ${ }^{1,2^{*}}$ (D) Zeleke Mekonnen ${ }^{1}$, Delenasaw Yewhalaw ${ }^{1,3}$ and Asrat Hailu ${ }^{4}$
}

\begin{abstract}
Background: Onchocerciasis (river blindness), caused by the filarial worm species Onchocerca volvulus, is a serious vector-borne neglected tropical disease (NTD) of public health and socioeconomic concern. It is transmitted through the bite of black flies of the genus Simulium, and manifested in dermal and ocular lesions. Ninety-nine percent of the total global risk and burden of onchocerciasis is in Africa. This scoping review examines the key challenges related to the elimination of onchocerciasis by 2020-2025 in Africa, and proposes recommendations to overcome the challenges and accelerate disease elimination. To find relevant articles published in peer-reviewed journals, a search of PubMed and Google Scholar databases was carried out.
\end{abstract}

Main text: Rigorous regional interventions carried out to control and eliminate onchocerciasis in the past four decades in Africa have been effective in bringing the disease burden under control; it is currently not a public health problem in most endemic areas. Notably, transmission of the parasite is interrupted in some hyperendemic localities. Recently, there has been a policy shift from control to complete disease elimination by 2020 in selected countries and by 2025 in the majority of endemic African countries. The WHO has published guidelines for stopping mass drug administration (MDA) and verifying the interruption of transmission and elimination of human onchocerciasis. Therefore, countries have revised their plans, established a goal of disease elimination in line with an evidence based decision to stop MDA and verify elimination, and incorporated it into their NTDs national master plans.

Nevertheless, challenges remain pertaining to the elimination of onchocerciasis in Africa. The challenge we review in this paper are: incomplete elimination mapping of all transmission zones, co-endemicity of onchocerciasis and loiasis, possible emergence of ivermectin resistance, uncoordinated cross-border elimination efforts, conflict and civil unrest, suboptimal program implementation, and technical and financial challenges. This paper also proposes recommendations to overcome the challenges and accelerate disease elimination. These are: a need for complete disease elimination mapping, a need for collaborative elimination activities between national programs, a need for a different drug distribution approach in conflict-affected areas, a need for routine monitoring and evaluation of MDA programs, a need for implementing alternative treatment strategies (ATSs) in areas with elimination anticipated beyond 2025, and a need for strong partnerships and continued funding.

(Continued on next page)

\footnotetext{
* Correspondence: gebruska2012@yahoo.com

${ }^{1}$ School of Medical Laboratory Sciences, Institute of Health Sciences, Jimma University, P.O. Box 378, Jimma, Ethiopia

${ }^{2}$ College of Veterinary Medicine, Samara University, Samara, Ethiopia

Full list of author information is available at the end of the article
}

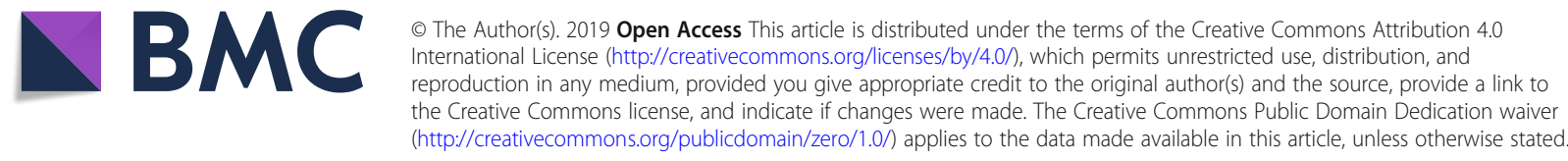


(Continued from previous page)

Conclusions: National programs need to regularly monitor and evaluate the performance and progress of their interventions, while envisaging the complete elimination of onchocerciasis from their territory. Factors hindering the targeted goal of interruption of parasite transmission need to be identified and remedial actions should be taken. If possible and appropriate, ATSs need to be implemented to accelerate disease elimination by 2025.

Keywords: Onchocerciasis, Elimination, Challenge, Africa

\section{Multilingual abstracts}

Please see Additional file 1 for translations of the abstract into the five official working languages of the United Nations.

\section{Background}

Onchocerciasis, also called river blindness, is a vectorborne parasitic neglected tropical disease (NTD) caused by the filarial nematode Onchocerca volvulus. It is transmitted through the bite of black flies of the genus Simulium that breed in fast-flowing water bodies [1]. It is estimated that nearly 37 million people are infected with onchocerciasis [2-4], and 200 million people are at risk of contracting the onchocerciasis infection [5]. Ninety-nine percent of the total global risk and burden is in Africa [6-10].

Onchocerciasis is a disease of major public health importance $[11,12]$. The disease is the world's second leading infectious cause of blindness after trachoma [13]. It is associated with reduced life expectancy $[14,15]$, and causes high mortality among onchocerciasis-blind people $[16,17]$ as well as epilepsy $[14,15,18-20]$. Onchocerciasis has also been associated with a variety of psychosocial and economic impacts. It results in social stigma of infected persons and their families [15, 21], disturbed sleep and reduced earnings among infected adults, poor school performance and a higher dropout rate among infected school-aged children [15, 22-27], and high health costs [4]. In fear of these occurring, communities migrate away from their fertile arable land [15, 28], cause drop in agricultural yields and perpetuate poverty.

Due to the high disease burden, the control of onchocerciasis has received considerable attention from various international organizations and donors. Concerted large-scale regional interventions carried out in the past four decades have been effective in bringing the disease burden under control; it is currently not a public health problem in most endemic areas in Africa [10, 29-31]. There is also established evidence that the disease is eliminated in some localized foci [28, 32-39]. Encouraged by these triumphs, the World Health Organization (WHO) established the target of onchocerciasis elimination in selected endemic countries by 2020 [40] and in remaining African countries by 2025 [41]. There is also international commitment to achieve the goal of disease elimination, as illustrated by the adoption of the World Health Assembly Resolution on NTDs (WHA 66.12) and endorsement of the London Declaration on NTDs of 2012 by pharmaceutical companies, donors, national governments, and non-governmental organizations (NGOs) [42]. In 2016, the WHO has published guidelines for stopping mass drug administration (MDA) and verifying the interruption of transmission and elimination of human onchocerciasis [43]. Onchocerciasis endemic countries have revised their plans, established a goal of disease elimination in line with an evidence based decision to stop MDA and verify elimination, incorporated it into their NTDs national master plans, and formed national onchocerciasis elimination committees to assist with and track elimination activities.

There are, however, many challenges to achieve the elimination of onchocerciasis in Africa [44-49]. This review examines the key challenges related to the elimination of onchocerciasis by 2020-2025 in Africa, and proposes recommendations to overcome the challenges and accelerate disease elimination. We believe that the review will help to inform many of the national programs working on the elimination of onchocerciasis in Africa.

\section{Main text}

To find relevant articles published in peer-reviewed journals, a search of PubMed and Google Scholar databases was carried out. Titles of articles and abstracts were reviewed. If found relevant full length articles were retrieved and accessed. Publications were included if the abstract or full content of an article focused on accomplishments and challenges of previous onchocerciasis control programs, and current status, progress and challenges of disease elimination in onchocerciasis endemic countries of Africa. Additional articles were identified and retrieved by looking at the references list of the publications. The search included only articles published in English language. Moreover, websites of ministries of health of endemic countries and international health organizations (WHO, the United States Agency for International Development, The Carter Center, and Sightsavers) were assessed to obtain relevant data on national elimination programs and technical documents, and reports of consultative meetings, respectively. Abstracts of conference 
proceedings, chapters of books, and press releases were also included.

\section{Previous regional interventions for onchocerciasis control and elimination in Africa}

Rigorous control interventions have been carried out to control and eliminate onchocerciasis in the past four decades in Africa. These include the Onchocerciasis Control Programme in West Africa (OCP) and the African Programme for Onchocerciasis Control (APOC).

The initial effort to control onchocerciasis was through the OCP, which ran from 1974 until 2002 in 11 West African countries that were most prevalent for the disease [29]. The OCP was initially a vector control program that was later complemented with MDA after ivermectin was registered for human use and donated for onchocerciasis control in 1987 [50]. At the OCP's end, onchocerciasis had been eliminated as a public health problem in all participating countries except Sierra Leone where operations were interrupted by a decade-long civil war, and 25 million hectares of land had been reclaimed for agricultural use [51].

The APOC was launched at the end of 1995 to eliminate the public health problem of onchocerciasis in 19 African countries outside the OCP zone [2, 52, 53], which had more than $80 \%$ of the global burden of the disease [54, 55]. In 2007, the APOC received the mandate to assist any of the OCP countries as required. The primary activities of the APOC were to map out the endemicity of onchocerciasis and detect high transmission areas eligible for mass treatment [15]. For a sustained and cost-effective distribution of ivermectin, the APOC employed annual community-directed treatment with ivermectin (CDTI) as its strategy [15, 56-58]. It covered more than 190000 communities, mainly in remote and hard-to-reach rural areas that were poorly serviced by health services, and lacked sufficient financial and human resources. This program effectively controlled the public health problem of onchocerciasis $[2,30,31,51$, 59-63]. The rationales and historical milestones of these two regional program are summarized in Table 1.

\section{Current status of onchocerciasis elimination in Africa}

After the APOC ended in 2015, it was replaced with the Expanded Special Project for Elimination of NTDs (ESPEN), which includes onchocerciasis elimination [63, 73, 74]. In accordance, onchocerciasis-endemic countries have shifted their policy from control to elimination and set an ultimate goal of interrupting parasite transmission from their territory. Elimination of onchocerciasis is defined as the "reduction of $O$. volvulus infection and transmission to the extent that interventions can be stopped, but post-intervention surveillance is still necessary" [75]. The WHO has published guidelines for stopping MDA and verifying the interruption of transmission and elimination of human onchocerciasis, which comprises three phases [43]:

Phase one is a phase of active transmission and MDA intervention, characterized by regular ivermectin treatment with a minimum requirement of $80 \%$ therapeutic coverage of the eligible population for 1215 years or longer in order to reach a point where transmission of the parasite can no longer be sustained. This has been supplemented with vector elimination efforts in selected onchocerciasis foci in Equatorial Guinea, Uganda, and Tanzania. At the end of this phase, programs perform epidemiological and entomological evaluations to demonstrate interruption of parasite transmission in order to stop MDA and move to the next phase. This includes testing children aged under 10 years and testing the heads of black flies for O. volvulus deoxyribonucleic acid (DNA) using Ov16 enzyme-linked immunosorbent assay (ELISA) and O-150 polymerase chain reaction (PCR) (pool screening), respectively.

Phase two is post-treatment surveillance (PTS) for new infections, lasting for 3-5 years. O-150 PCR testing is used to confirm the interruption of $O$. volvulus transmission in black flies. When O-150 PCR results are at or near the threshold (< one infected black fly in 2000 total flies), the Ov-16 serology test is used to confirm the interruption of parasite transmission in children. Moreover, Ov-16 serology is used to confirm the interruption of parasite transmission in some areas of Africa where vector elimination has been achieved. If confirmed the program enters the last phase.

Phase three is a period of post-elimination surveillance to detect possible reintroductions of onchocerciasis [43]. This phase confirms permanent interruption or elimination of the disease in a defined geographic area [76]. The WHO's three-phase elimination guidelines are briefly depicted in Fig. 1.

It is acknowledged that the initial goal of elimination of onchocerciasis as a disease of public health importance has been achieved in endemic areas of Africa including even where the endemicity of the disease was extremely high. The feasibility of elimination of onchocerciasis has also been confirmed in limited endemic foci in the last decade [28, 32-39].

\section{The major challenges relating to onchocerciasis elimination in Africa}

In spite of this evidence that assures that the elimination of onchocerciasis from the continent is feasible, there are challenges regarding the accomplishment of this by 
Table 1 Summary of onchocerciasis control programmes in Africa: countries covered, objectives, strategies and achievements made at their closure

\begin{tabular}{|c|c|c|c|c|c|}
\hline Program & Countries covered & Objective & Strategies & Achievements & References \\
\hline $\begin{array}{l}\text { OCP } \\
(1974-2002)\end{array}$ & $\begin{array}{l}\text { Benin, Burkina-Faso, } \\
\text { Cote d'Ivoire, Ghana, } \\
\text { Guinea, Guinea-Bissau, } \\
\text { Mali, Niger, Senegal, } \\
\text { Sierra Leone, Togo } \\
\text { (SIZ in Togo and Sierra } \\
\text { Leone for the period } \\
\text { 2002-2007) }\end{array}$ & $\begin{array}{l}\text { To eliminate } \\
\text { onchocerciasis } \\
\text { as a disease of } \\
\text { public health } \\
\text { importance and } \\
\text { an obstacle to } \\
\text { socio-economic } \\
\text { development, and } \\
\text { to ensure participating } \\
\text { countries can maintain } \\
\text { achievement }\end{array}$ & $\begin{array}{l}\text { (1) Vector control, } \\
\text { (2) Both vector } \\
\text { control and CDTI, } \\
\text { (3) CDTI only } \\
\text { (in specific countries or areas) }\end{array}$ & $\begin{array}{l}\text { Eliminated public health } \\
\text { impact of onchocerciasis, } \\
\text { Reclaimed } 25 \text { million } \mathrm{km}^{2} \\
\text { abandoned land for agriculture, } \\
\text { Prevented } 600000 \text { cases } \\
\text { of blindness, } \\
\text { Freed } 18 \text { million children from } \\
\text { risk of blindness } \\
\text { Infection disappeared from an } \\
\text { estimated } 1 \text { million individuals } \\
\text { Enhanced human resource } \\
\text { capacity building via training of } \\
\text { more than } 400 \text { professional staff } \\
\text { Reduced disease associated social } \\
\text { stigma } \\
20 \% \text { economic rate of return }\end{array}$ & $\begin{array}{l}{[29-31,50,51} \\
64-71]\end{array}$ \\
\hline $\begin{array}{l}\text { APOC } \\
(1995-2015)\end{array}$ & $\begin{array}{l}\text { Angola, Burundi, } \\
\text { Cameroon, Central } \\
\text { African Republic (CAR) } \\
\text {, Chad, Democratic } \\
\text { Republic of Congo } \\
\text { (DRC), Equatorial Guinea, } \\
\text { Ethiopia, Gabon, Kenya, } \\
\text { Liberia, Malawi, } \\
\text { Mozambique, Nigeria, } \\
\text { Rwanda, Uganda, } \\
\text { Tanzania, Sudan }\end{array}$ & $\begin{array}{l}\text { To eliminate } \\
\text { onchocerciasis as } \\
\text { a disease of public } \\
\text { health importance } \\
\text { in the remaining } \\
\text { endemic countries } \\
\text { in Africa }\end{array}$ & $\begin{array}{l}\text { The establishment of } \\
\text { sustainable CDTI and } \\
\text { vector control with } \\
\text { environmentally-safe } \\
\text { methods where appropriate. }\end{array}$ & $\begin{array}{l}\text { Eliminated onchocerciasis as a } \\
\text { disease of public health importance } \\
\text { Saved } 19 \text { million disability-adjusted } \\
\text { life years during its } 20 \text {-year existence } \\
20 \% \text { decline in the disability-adjusted } \\
\text { life year burden of onchocerciasis } \\
\text { between } 2005 \text { and } 2015 \text { at a cost of } \\
\text { only USD } 27 \text { per disability-adjusted life year } \\
\text { Evidences of elimination of onchocerciasis } \\
\text { in some localized foci }\end{array}$ & $\begin{array}{l}{[2,3,15,28,33-} \\
39,56,57,59- \\
62,69,72]\end{array}$ \\
\hline
\end{tabular}

CDTI Community-directed treatment with ivermectin, OCP Onchocerciasis Control Programme in West Africa, USD United States dollar

2025 [44-49]. The major challenges pertaining to the elimination of onchocerciasis in Africa are:

- incomplete elimination mapping of all transmission zones;

- co-endemicity of onchocerciasis and loiasis;

- possible emergence of ivermectin resistance;

- uncoordinated cross-border elimination efforts;

- conflict and civil war;

- suboptimal program implementation; and

- technical and financial challenges.

Incomplete elimination mapping of all transmission zones In the control era, the primary task was to define the geographic distribution of onchocerciasis and delineate potentially endemic communities [77-80] via the rapid epidemiological mapping of onchocerciasis (REMO) strategy [81]. Areas with a prevalence of infection greater than $20 \%$ nodule prevalence in adult men in a community were defined as high-risk areas (mesoendemic and hyperendemic). These areas were associated with a significant risk of onchocerciasis disease [31] and it was decided that mass ivermectin treatment should be implemented forever [10, 79]. Indeed, successful progress is being made to interrupt transmission of the parasite in these areas [82]. The challenge lies with areas that are considered hypoendemic and nonendemic, where there is less than $20 \%$ onchocercal nodule prevalence [31, 83], which were excluded from treatment $[84,85]$ as it was decided that the level of infection did not constitute a serious public health problem. Now, the shift toward disease elimination has brought a new mapping challenge [86], as these disregarded hypoendemic areas might have contributed to sustained transmission and spread of infection [87-89], and become an impediment to disease elimination [90, 91]. Furthermore, despite a number of countries devising their own mapping strategy, a standardized common elimination mapping guideline is not yet available to complete the process.

\section{Co-endemicity of onchocerciasis and loiasis}

Loiasis is a filarial disease caused by the nematode parasite Loa loa [92]. It is estimated that 12-13 million people are infected in Africa [70]. The rapid mapping of parasite distribution revealed that there is a high prevalence of loiasis in two large foci in Africa, namely the west and east foci. The west focus includes southeast Nigeria, south Cameroon, Equatorial Guinea, Gabon, west Congo, the coastal plains of Angola, Bas-Congo in the Democratic Republic of the Congo (DRC), west Central African Republic (CAR), and south Chad. The east focus covers east CAR, south of South Sudan, and northeast DRC [92]. A small focus is found at the boundary between Kenya and South Sudan. The areas with low prevalence stretch from 


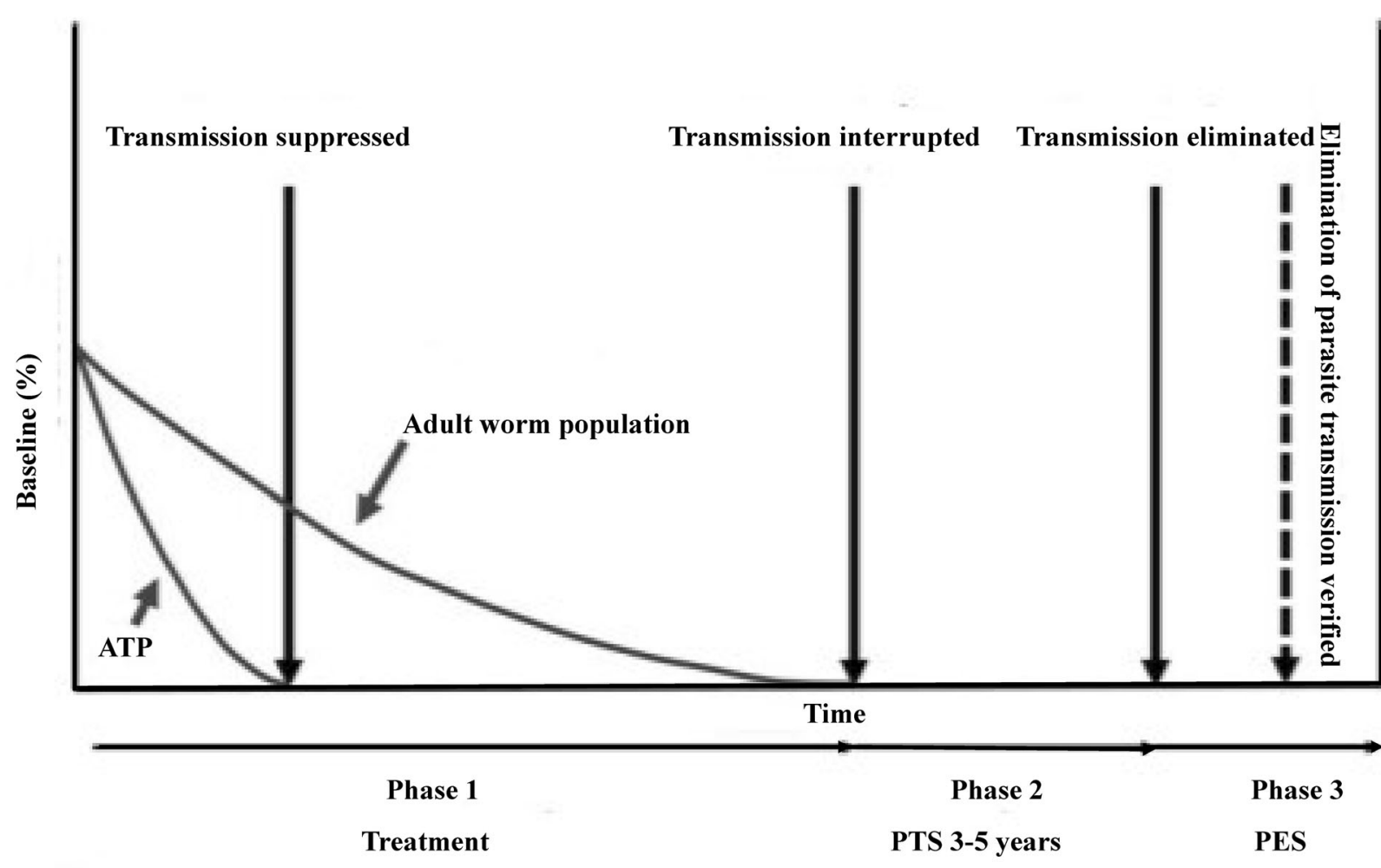

ATP: Annual Transmission Potential

PTS: Post-Treatment Epidemiological Surveillance

PES: Post-Elimination Surveillance

Fig. 1 Phases in the elimination of human onchocerciasis (Source: [43])

southwest Benin to west Ethiopia, and from north Angola to central Chad [44]. Figure 2 is map of estimated prevalence of $L$. loa in Africa throughout history.

L. loa causes ocular and systemic manifestations with minor effects on the quality of life [44]. The issue is that in areas co-endemic with onchocerciasis, ivermectin treatment of individuals harbouring high $L$. loa microfilariemia causes serious neurological adverse events that might lead to death [85, 90, 93-96]. The risk of severe adverse events is high when the microfilaria load exceed $8000 \mathrm{microfilaria} / \mathrm{ml}$, and the reaction is more severe if the load exceeds 30000 microfilaria/ml [93, 97-99]. As a result, millions of people living in areas where loiasis is co-endemic with onchocerciasis are left untreated with the standard strategy of community-wide ivermectin treatment $[49,85,92]$. Even in areas where treatment has been conducted under close surveillance to manage severe adverse effects, there is a high refusal rate to swallow the drug [74, 99] due to fear of risk of adverse events. This has contributed to the sustained transmission, reintroduction of the parasite into previously eliminated areas [49], and finally to it posing a major obstacle in the elimination of onchocerciasis $[10,85,93,94,96,100]$.
Possible emergence of ivermectin resistance

Ivermectin has long been used to control onchocerciasis $[101,102]$. It is an effective microfilaricidal drug with a partial macrofilaricidal property when used repetitively: annually, semi-annually, or quarterly [103-105]. It should be noted that, despite several rounds of treatment, there are reports of $O$. volvulus responding poorly to the antifecundity effect of ivermectin in Ghana [106-109] and Cameroon [110, 111]. These observations raise the possibility that ivermectin resistance is emerging. This is supported by several parasite genetic studies that showed the occurrence of polymorphisms or changes in specific genes responsible for suboptimal responses in parasite populations exposed to several years of ivermectin treatment [112-120]. In 2017, a genome-wide analysis of O. volvulus revealed that evolution of suboptimal responses to ivermectin is determined by selective sweeps of pre-existing quantitative trait loci with many genes contributing in a polygenic manner [121]. Researchers examining human genes affecting drug response and clinical outcomes have reported that host genetic polymorphisms might be attributed to a varied response to ivermectin treatment in Ghana [122]. This phenomenon could jeopardize the goal 


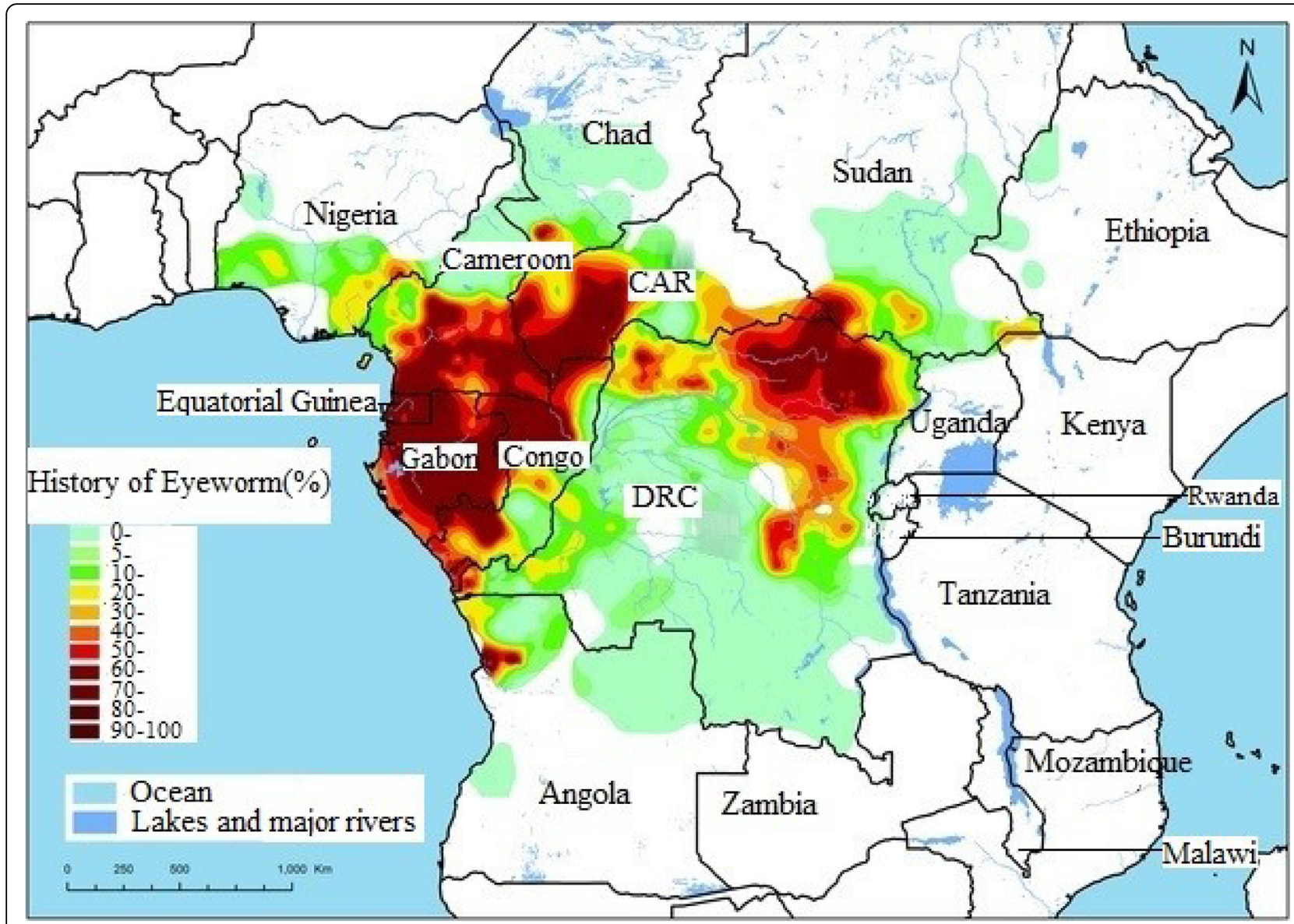

Fig. 2 Map showing the estimated prevalence rates of Loa loa in Africa throughout history (Source: [92])

of disease elimination, as ivermectin is still being used as the drug of choice in the elimination of onchocerciasis in Africa.

\section{Uncoordinated cross-border elimination efforts}

As onchocerciasis is extensively prevalent in a wide range of African countries, there are several cross-border issues that affect efforts of national programs working to achieve disease elimination [123]. These include international boundaries transversing disease transmission zones, and human population and vector migration [70, 89].

Endemic countries, mainly those with high-risk areas [1], have several shared transmission zones across their national borders $[1,70,123]$. This is because rivers, which offer breeding sites for black flies, often form borders between countries [30]. Elimination efforts along borders of countries with shared transmission zones might be uncoordinated [123] and MDA activities might be at different stages of implementation. This might therefore contribute to sustained transmission of infection and hinder disease elimination. For example, despite good progress made in achieving interruption of transmission in a number of foci in Uganda, recurrent transmission of onchocerciasis from cross-border areas of the DRC and South Sudan, where onchocerciasis is still endemic, poses a challenge [10, 91, 124, 125]. A similar problem of crossborder transmission of onchocerciasis has been reported in Malawi and Guinea-Bissau, with a possible source from adjacent border areas of Mozambique and Guinea, respectively [86]. In addition to international cross-border issues, internal administrative border issues within a country can also lead to significant challenges in the elimination of onchocerciasis [126] as CDTI projects in a country could be in different stage of programme implementation. Table 2 outlines the endemic countries in Africa and their respective cross-border endemic locations.

Human population and black fly migration across national borders also has a significant impact on the elimination of onchocerciasis in Africa [70, 127]. There is seasonal population migration from one country to another, or from one area of a country to another, for several activities such as fishing, farming and mining. Infected migrating people either spread the infection into diseasefree areas or disease-free migrating persons acquire infections from an onchocerciasis-endemic area to which they arrive. For instance, reinfection of a community nearly free 
Table 2 Onchocerciasis endemic countries and their shared cross-border locations (Source: [126])

\begin{tabular}{|c|c|}
\hline Country & Shared cross-border endemic location with \\
\hline Angola & DRC \\
\hline Benin & Togo, Nigeria, Burkina Faso \\
\hline Burkina Faso & Mali, Cote d'Ivoire, Ghana, Togo, Benin, Niger \\
\hline Cameroon & Nigeria, Chad, Congo-Brazzaville, CAR \\
\hline CAR & Cameroon, Chad, South Sudan \\
\hline Chad & Cameroon, CAR, South Sudan \\
\hline $\begin{array}{l}\text { Congo- } \\
\text { Brazzaville }\end{array}$ & Cameroon, Gabon, DRC \\
\hline Cote d'Ivoire & Liberia, Burkina Faso, Ghana, Mali \\
\hline DRC & Uganda, Angola, CAR, Congo, South Sudan, Zambia \\
\hline $\begin{array}{l}\text { Equatorial } \\
\text { Guinea }\end{array}$ & Cameroon, Gabon \\
\hline Ethiopia & Sudan, South Sudan \\
\hline Gabon & Cameroon, Congo \\
\hline Ghana & Cote d'Ivoire, Burkina Faso, Togo \\
\hline Guinea & Guinea Bissau, Senegal, Mali, Sierra Leone, Liberia \\
\hline Guinea Bissau & Senegal, Guinea \\
\hline Kenya & South Sudan, Tanzania \\
\hline Liberia & Sierra Leone, Guinea, Cote d'Ivoire \\
\hline Malawi & Mozambique \\
\hline Mali & $\begin{array}{l}\text { Senegal, Guinea, Cote d'Ivoire, Burkina Faso, Benin, } \\
\text { Niger }\end{array}$ \\
\hline Mozambique & Malawi, Tanzania \\
\hline Nigeria & Benin, Cameroon, Chad, Niger \\
\hline Niger & Burkina Faso, Benin, Nigeria, Chad, Mali \\
\hline Senegal & Guinea-Bissau, Guinea \\
\hline Sierra Leone & Guinea, Liberia \\
\hline South Sudan & Uganda, Ethiopia, Sudan \\
\hline Sudan & Ethiopia, South Sudan \\
\hline Togo & Benin, Ghana, Burkina Faso \\
\hline Tanzania & Mozambique, Burundi, Kenya \\
\hline Uganda & DRC, South Sudan \\
\hline
\end{tabular}

CAR Central Africa Republic, DRC Democratic Republic of the Congo

from onchocerciasis in Burkina Faso was due to migration of infected persons from neighbouring onchocerciasisendemic zones of Côte d'Ivoire [128].

In addition to human migration, cross-border vector flying contributes to the dispersal of parasites and reinvasion of disease-free areas, as observed in the previous OCP areas [75, 127, 129, 130]. Savanna black flies can travel up to 600 kilometers [131] with a wind assisted flight and maintain transmission at the point of their arrival despite a presence of local intervention [127]. A group of researchers indicated that migrating flies were one of the possible factors for the reintroduction of infection into the previously disease-free OCP areas of Burkina Faso [132]. Similarly, cross-border migration of vectors might have partly contributed to the persistence of infection and ongoing transmission of $O$. volvulus in the river basin areas of northern and central Togo despite decades of vector control and MDA intervention [133]. Apart from international borders, human and black fly migration can also carry and disperse parasites between local foci within a country [74].

\section{Conflict and civil war}

The presence of conflict and civil war in some African countries is another impediment in the elimination of onchocerciasis $[9,71]$. Conflict interrupts interventions and weakens political support [9], and is thus responsible for the occurrence of new cases of onchocerciasis-related blindness every year [10]. Conflict and post-conflict African countries that have anticipated delayed achievement of disease elimination include South Sudan, the DRC, CAR, Angola, and Côte d'Ivoire [9, 70, 134]. In countries with such a crisis, the healthcare system is fragmented [135], and it is difficult to obtain access to deliver regular MDA and carry out entomological and epidemiological surveillances activities [136] for monitoring and evaluation of program intervention. For instance, in 2016, MDA was seriously disrupted and the number of treatments declined to 196000 (from 462000 in 2015) due to deteriorating security in South Sudan [137]. People are displaced from their original residences, marginalized from receiving ivermectin treatment on a regular basis [68], and may serve as reservoirs of infection [136].

\section{Suboptimal program implementation}

There are different programmatic factors that affect the elimination of onchocerciasis in Africa, including the extent of drug coverage (i.e. geographic and therapeutic), compliance to CDTI $[138,139]$, and frequency of mass ivermectin treatment [131]. Geographical coverage is defined as the proportion of administrative units treated out of the total number of units requiring treatment in a particular MDA program [140, 141]. It is an indicator of the scaling up of the MDA program in a country [140]. Therapeutic coverage is defined as the percentage of the eligible population that participates in a CDTI program in a given area [62].

Achieving and maintaining high geographic and therapeutic coverage during each MDA round will help to shorten the period needed to interrupt parasite transmission [142]. Trends in ivermectin therapeutic coverage in 26 countries of Africa are presented in Table 3 and Fig. 3. According to the WHO's Weekly Epidemiological Record, a total of 53865599 people received treatment in 2007 in Africa [143]. This number has increased each year, and a reported 132502932 people received treatment at least once in 2016 [143-152]. Therapeutic 


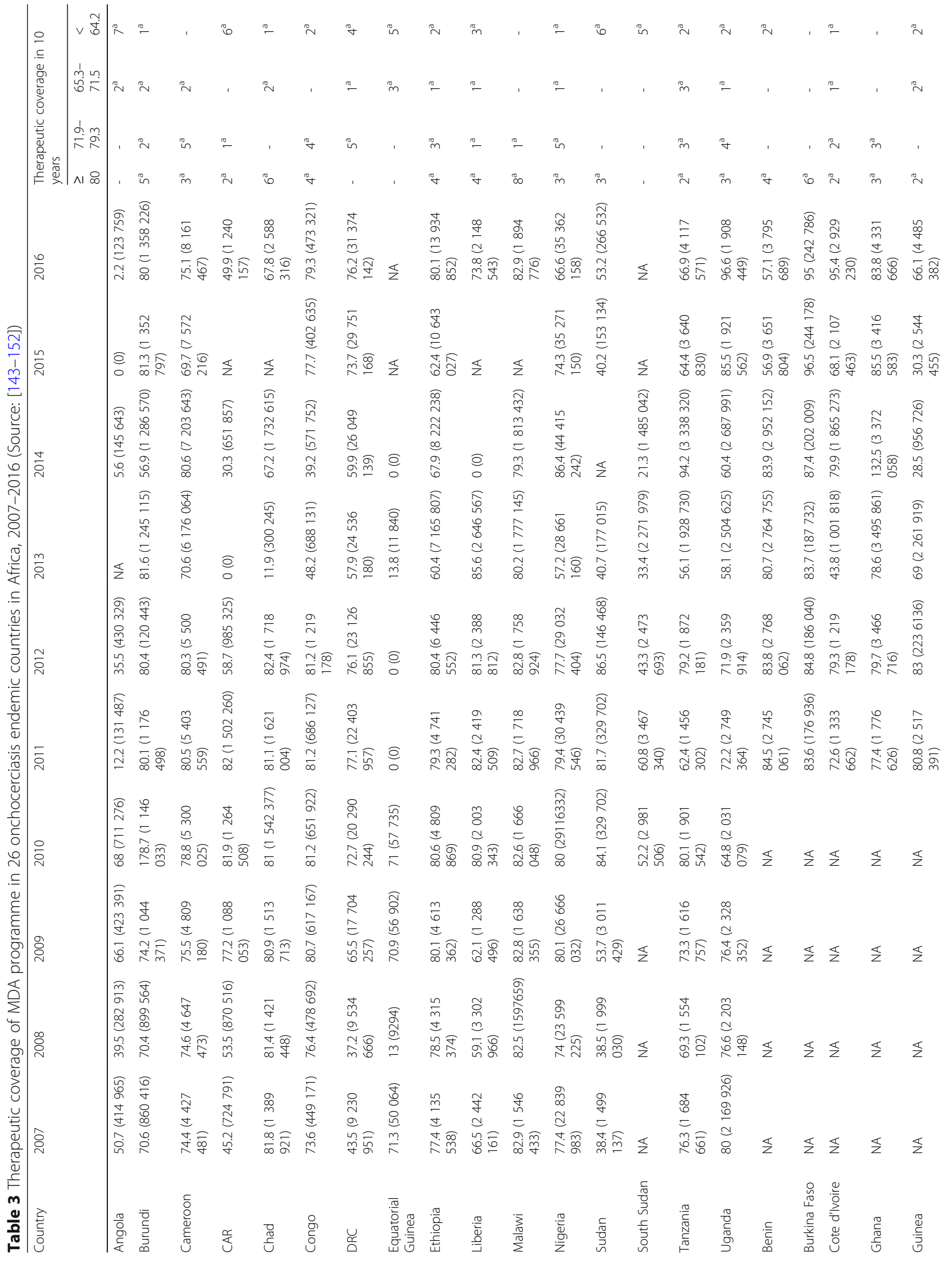




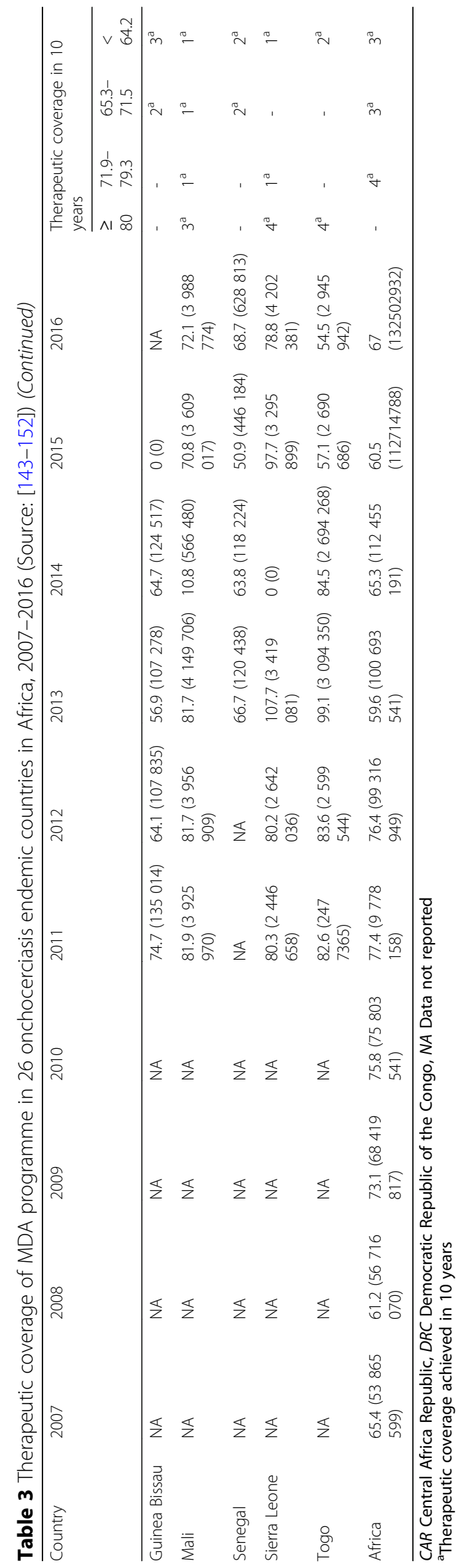



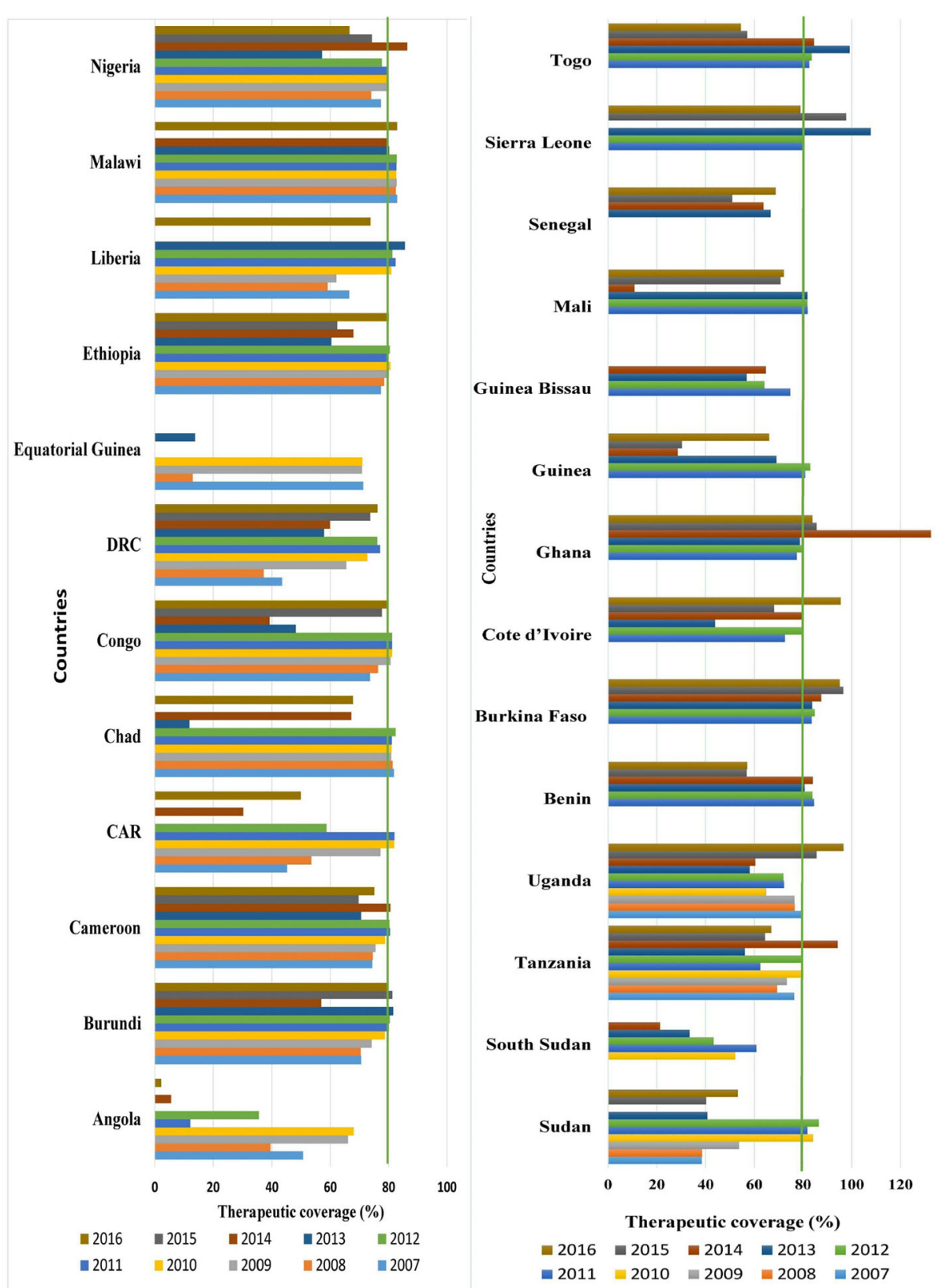

Fig. 3 Temporal trends of therapeutic coverage of MDA in 26 onchocerciasis-endemic countries in Africa, 2007-2016 (Source: [143-152])

coverage was $65.4 \%$ in $2007,61.2 \%$ in $2008,73.1 \%$ in $2009,75.8 \%$ in $2010,77.4 \%$ in $2011,76.4 \%$ in 2012 , $59.6 \%$ in $2013,65.3 \%$ in $2014,60.5 \%$ in 2015 , and $67 \%$ in 2016 (see Table 3 and Fig. 3). This shows that, continentally, the minimum threshold required for interruption of parasite transmission has not yet been reached. Though it is fluctuating, individual country data show that most countries have achieved the effective threshold required to control the disease over 10 years. Therapeutic coverage above the minimum disease elimination threshold (80\%) was also reported: Malawi has achieved this in 8 years; Burundi and Burkina Faso in six; Chad in five; Congo, Ethiopia, Liberia, Benin, Sierra Leone, and Togo in four; and Cameroon, Ghana, Mali, Nigeria, Uganda, and Sudan in 3 years over 10 years. Angola, the DRC, CAR, Equatorial Guinea, and South Sudan had poor therapeutic coverage during the MDA period (see Table 3 and Fig. 3). Key factors for poor drug coverage that hamper reaching the recommended threshold include: co-endemicity with loiasis [135], shortage of drug supply [146], and logistical challenge of delivering ivermectin to endemic areas in a timely manner [10, 151], 
mainly to those living in remote and hard-to-reach endemic areas [44, 74, 153]. To achieve elimination as quickly as possible, adequate support needs to be provided to national programs with poor drug coverage to scale up their mass ivermectin treatment.

Compliance is another critical programmatic issue that should be considered in the elimination of onchocerciasis in Africa. It refers to the frequency with which individuals comply to swallow the provided drugs [141]. It has been found that not all eligible members of a community swallow the drug they receive during a MDA campaign and a wide range of factors are affecting compliance to CDTI [135, 141, 154-169]. For instance, compliance to CDTI was associated with older age [165, 167], perceived individual's risk of onchocerciasis infection [157, 162, 163, 165], perceived belief of benefits of ivermectin [154, 157, 159, 162, 167, 169], positive beliefs as community drug distributors (CDDs) are doing their job well $[157,163,165]$, whereas being female and individual's past experience of drug adverse effects were associated with non-compliance to CDTI [168]. There are also individuals in a community who fail to comply over several years of annual CDTI, known as systematic non-compliers. They account for more than $10 \%$ of a population [166] that might act as a reservoir of infection, which maintains transmission of the parasite $[141,166,168]$, thus making interrupting the transmission challenging [74].

Frequency of mass ivermectin treatment is another programmatic factor that affects the elimination of onchocerciasis. When control was the agenda of control programs, annual treatments appeared to be sufficient to eliminate the public health and socioeconomic impact of onchocerciasis. With the shift to the agenda of elimination, the annual mass ivermectin treatment approach is questionable [131], particularly in settings with high pre-control endemicity and areas where CDTI has recently started [9, 49]. For instance, a large-scale epidemiological evaluation of CDTI areas showed that more than 20 years of annual CDTI with adequate coverage was not able to interrupt parasite transmission in Touboro, north Cameroon, an area with the highest recorded pre-control endemicity level [30]. Model-based comparisons of annual and biannual treatments also concluded that biannual treatments would reduce the number of treatment years by one third compared to annual treatments in highly endemic areas $[49,142,170]$. Biannual and/or quarterly MDA was found to be critical for the interruption of parasite transmission in Latin American endemic countries [30].

\section{Technical and financial challenges}

With the conclusion of the APOC and shift to ESPEN in 2016, interventions for other NTDs are integrated into the program for onchocerciasis elimination [73]. This has brought changes to the well-functioning community MDA approach for onchocerciasis and added a load to the minimally educated and unpaid CDDs [171]. There are also technical challenges to integrating disease-specific MDA programs [172] with different implementation units into a combined NTDs platform [45, 173, 174]. Moreover, thorough scientific evidence is needed to confirm interruption of transmission and verification of elimination using specialized and quality-assured laboratory facilities and diagnostic tools [71]. Well-trained field entomologists are also required to collect entomological data to monitor and evaluate program performance.

Adequate funding is always crucial to any effort toward the control or elimination of any disease. In the past four decades of onchocerciasis control, endemic countries relied on external financial aid from international donor organizations. The core principle of the APOC was to create government-supported self-sustainable community programs. However, it is evidenced that governments of endemic countries were often unable to offer sufficient financial resources to their onchocerciasis projects in the APOC era $[56,175,176]$. They even failed to do so when the APOC came to its end in 2015 [173]. This was complemented by decreased donors' interest to support the program [177]. The current program, ESPEN, is also not a major funding organization. It was established to ensure that endemic countries take ownership of their national programs [178] and to coordinate the technical support for the interventions of five NTDs including onchocerciasis $[30,73]$. Inadequate funding is, therefore, a challenge that could prevent the realization of complete elimination of onchocerciasis in Africa.

Sustainability of CDTI necessitates continued education and mobilization of the community, supervision, communication, and human resource capacity-building via refresher or regular training of community leaders, CDDs, frontline health workers, district managers, regional-level implementers, and national program managers during every round of MDA [45]. These are continuing costs to the elimination programs [45] that need adequate financial resources as a proportion of health budgets [141], particularly in areas that commenced to implement biannual mass treatments to achieve their elimination target $[9,179]$. Another critical issue is maintaining the motivation and willingness of unpaid and volunteer community workers who distribute the donated drug in their communities. Low motivation and high attrition rates of CDDs have been identified in many endemic countries $[135,180]$. Lack of incentive or remuneration has been identified as one of the causes [135]. The work of CDDs is even more overloaded in the current ESPEN with integrated interventions for NTDs [181, 182], which might eventually diminish their performance [171]. Given the value of their role in the elimination of 
onchocerciasis, incentives have to be provided to keep CDDs motivated to perform their job effectively [183]. It has also been found that incentives in various forms for community volunteers have been shown to enhance program delivery and community participation [181, 184, 185].

Moreover, as country programs advance toward the endpoint, it is essential to implement complete elimination mapping in previously untreated or hypoendemic areas (which are geographically vast and hard to reach for health services) [186] and follow the progress of elimination efforts [187]. These two key activities demand the utilization of the WHO's recommended tools and costly laboratory operations [179]. For example, in the course of eliminating onchocerciasis in Uganda, the annual cost of laboratory procedures was about United States dollars (USD) 35 000-40 000 [177]. This might be higher in countries that do not have their own national molecular laboratory settings for processing samples. Therefore, given the increased scope of elimination activities, financial constraints remain among the chief concerns of national programs for the elimination of onchocerciasis in Africa [96, 173].

\section{Recommendations to overcome the challenges and accelerate onchocerciasis elimination}

The elimination of onchocerciasis by 2025 requires the criteria for stopping MDA to be achieved by latest 2022 [75] so that PTS can begin [188]. Countries need to evaluate and regularly monitor their national programs and identify the major challenges impeding the targeted interruption of parasite transmission. Recommendations to overcome the aforementioned challenges and suggested actions to accelerate the elimination of onchocerciasis by 2025 include:

- a need for complete disease elimination mapping;

- a need for collaborative elimination activities between national programs;

- a need for a different drug distribution approach in conflict-affected areas;

- a need for routine monitoring and evaluation of MDA programs;

- a need for implementing alternative treatment strategies (ATSs) in areas with elimination anticipated beyond 2025; and

- a need for strong partnerships and continued funding.

\section{A need for complete disease elimination mapping}

The transition from the goal of control to elimination of onchocerciasis from all endemic areas of Africa [85] necessitates the revision of deployed approaches in order to define the distribution of onchocerciasis [179, 189] and thus the implementation of MDA [82]. The decision to implement mass treatment needs to be based on the presence or absence of the transmission of infection [88]. All geographic areas where sustained local transmission of the parasite is likely but that were previously excluded from control programs as nonendemic or hypoendemic need to be mapped $[127,189]$. The WHO recommends the Ov-16 serological test [82, 88, 127] for onchocerciasis elimination mapping to determine eligibility for MDA, as this would help to detect a status of infection and parasite transmission at a low level of endemicity [86, 127]. If it is proven that there is sustained transmission of the parasite [189], programs should implement an appropriate intervention [178, 189]. The onchocerciasis elimination mapping, therefore, helps to focus intervention in areas where parasite transmission is definitely happening [89]. According to the WHO Onchocerciasis Technical Advisory Subgroup 1st meeting report of 2018, the provisional threshold for commencing mass ivermectin treatment is set at $2 \% \mathrm{Ov}-16$ seropositivity [82]. The Ov-16 serology for elimination mapping offers a more sensitive indicator of infection [190]. However, there are concerns pertaining to the tool measuring infection and transmission as it does not differentiate active infection from previous exposure to infection with full certainty. It is not clear how to interpret serological data from surveys in hypoendemic areas. There are also debates among experts on the criteria for deciding and implementing MDA. It is, therefore, necessary to establish a measurable threshold to identify the status of local transmission in hypoendemic areas by considering the tool's test performance $[127,189]$. The WHO needs to avail a standardized onchocerciasis elimination mapping strategy that guides national elimination programs in Africa to accomplish their disease mapping.

\section{A need for collaborative elimination activities between national programs}

Cross-border foci will require a high degree of political, managerial, and scientific coordination between the respective parties involved to ensure complete success in eliminating onchocerciasis [44]. National elimination programs of neighbouring countries need to undertake coordinated and collaborated cross-border elimination activities [71, 92] to ensure that cross-border issues do not affect the progress toward elimination. Key activities that could be carried out in a collaborative manner between national programs include: routine and continuous communication for common understanding [126], reaching all their adjoining endemic areas of countries with MDA, harmonizing MDA and surveillance activities, and sharing of data, best practices, and successful approaches [71, 123]. For example, crossborder collaboration in the control of onchocerciasis in Mano River Basin countries is exemplary in that it 
provides valuable lessons to carry out an effective MDA for the elimination onchocerciasis and other NTDs [123] which can be applied for other African countries faced with cross-border transmission of infection. Moreover, routine entomological studies need to be carried out to evaluate the risk of reintroduction of infection via vector migration in areas where cessation of ivermectin distribution is being considered [75].

\section{A need for a different drug distribution approach in conflict-affected areas}

There is disruption of the population structure due to extensive migration and resettlement in conflict-affected areas [141]. Thus, the MDA strategy carried out in conflict areas needs to be different from the CDTI approach in usual situations [74]. MDA in a conflict area could be carried out through collaboration with local NGOs or humanitarian organizations, whose volunteers are often present in war zones to achieve an improved geographic coverage of ivermectin [74]. Moreover, migrant and displaced people need to be outreached during MDA campaigns at their destinations via appropriate strategies [139]. For instance, either CDDs from hosting areas should be trained to include migrant and displaced people during the drug distribution period or drug distributors from among migrant/displaced people need to be trained.

\section{A need for routine monitoring and evaluation of MDA programs}

To interrupt the transmission of onchocerciasis, monitoring and evaluation of MDA impact on infection and transmission, and evaluation of the decline in infection levels is crucial [88]. This will help to identify areas that are not performing well in an elimination program [88]. The WHO has published guidelines for stopping MDA and the evidence required for verification of interruption of transmission in 2016. The guidelines specify that routine entomological and serological monitoring and evaluation should occur at least every 4-5 years according to local regional guidelines [43]. Despite this, there are issues with the criteria for evaluating progress toward elimination, which need revision. To determine whether MDA can be safely stopped and detect a prevalence of less than $0.1 \%$ threshold, the 2016 WHO guidelines state that a sample size 1000-2000 children aged below 10 years need to be tested [43]. However, the Ov16 ELISA has a sensitivity of $80 \%$ and specificity of $97 \%$ [192]. A test with $97 \%$ specificity cannot measure $0.1 \%$. It is not therefore possible to reach this threshold with the test performance (specificity) of the current diagnostic tool [191]. To be successful at detecting less than $0.1 \%$ threshold needs a test that achieves greater than 99.9\% specificity [191], and a large sample size is needed
[74]. Hence, with this threshold, areas where transmission has been interrupted will fail to meet the criterion and demand to carry on unwarranted MDA [192]. As many national onchocerciasis programs with several years of CDTI under their belt are now preparing to apply this guidance, it is important that the current threshold for MDA cessation be revised [191].

Furthermore, successful elimination of onchocerciasis requires routine monitoring of factors that may affect program sustainability and evaluation of progress of CDTI interventions. Drug coverage verification surveys need to be carried out carefully and on a regular basis following campaigns $[140,194,195]$ to identify communities with low therapeutic coverage $[193,196]$, and then to enable changes to be made to MDA implementation [140]. The participation of the community and compliance to CDTI need to be monitored, and factors associated with non-compliance should be identified. Emphasis should be given to identifying systematic non-compilers. A community's awareness and correct perception of onchocerciasis and MDA is important for successful implementation and sustainability of a CDTI program [197]. Community-based social research is also needed to determine the community's awareness and perception of onchocerciasis [74] and other factors contributing to program weakness [45]. Community awareness should be sustained through consistent social mobilization and health education [141]. Moreover, it is worth bearing in mind that long-term use of ivermectin could induce selection pressure on the parasite genome for the occurrence of drug resistance. This should be monitored regularly by carrying out genetic-based studies using molecular markers. Above all, it should be emphasized that national elimination programs need to expand drug coverage to all geographic areas and eligible members of communities to achieve interruption of parasite transmission and ultimately ensure disease elimination $[151,152]$.

\section{A need for implementing ATSs in areas with elimination anticipated beyond 2025}

Endemic areas where it is anticipated that interruption of transmission will occur after 2025 may require ATSs to accelerate infection decline toward elimination [127]. These include enhanced CDTI, use of other drugs, complementary vector control, and testand-treat strategies [46, 85, 139].

An enhanced CDTI (biannual or pluriannual) approach could be used to target complicated areas, for instance, those where annual CDTI has not interrupted transmission after a long time of treatment [127], and those with no or only a short history of treatment [49]. A similar approach could also be followed in communities with poor ivermectin responses and areas where 
elimination activities are frequently interrupted due to conflict and civil unrest [139].

Alternative drugs or therapies can also be applied to areas where CDTI cannot be implemented effectively $[71,85,127]$, or in areas where program implementation is considered to be insufficient [139]. New therapies to eliminate onchocerciasis have also been developed [46, 139]. After decades of clinical trials [198-200], the United States Food and Drug Administration (US FDA) has approved moxidectin for the treatment of onchocerciasis [201-204]. Moxidectin has superior clinical efficacy $[183,198]$ and a better safety profile compared to ivermectin [46, 200]. This could potentially improve a community's participation during MDA, particularly regarding systematic non-compliers [205]. If made available to endemic countries, moxidectin could help to accelerate the progress toward onchocerciasis elimination [204], including in those areas with suboptimal responses to ivermectin [200]. Another alternative antibiotic targeting Wolbachia endosymbionts of $O$. volvulus could also be used within test-and-not-treat strategies [46], primarily in areas coendemic with loiasis [206]. This can be achieved using doxycycline, which is currently the only usable macrofilaricide [207]. Vector control, using WHO approved and environmentally safe insecticides [188], is also a known alternative strategy for eliminating the black fly or reducing its density to levels where the disease is eliminated [208]. Therefore, localized vector control could be considered in high-transmission settings where MDA alone is not sufficient to interrupt transmission of the parasite [49] and areas where onchocerciasis is co-endemic with loiasis [85]. The WHO/ APOC guide for decision making and implementation of vector control as ATSs for elimination of onchocerciasis (WHO/MG/15.22) also recommends the implementation of vector control as an alternative strategy to accelerate the elimination of onchocerciasis [188].

\section{A need for strong partnerships and continued funding}

The successes of previous control programs can be, at least partly, attributed to strong partnerships among different stakeholders, including: international donors; the WHO, with its technical guidance and support; Merck pharmaceutical, with its donation of Mectizan ${ }^{\circ}$ and all importation costs covered; governments of endemic countries; NGOs working closely with governments of endemic countries, in terms of their financial and technical support; and communities. All these bodies and groups contributed to the elimination of onchocerciasis as a public health problem in endemic areas of Africa [178].

The relevance of strong partnerships and a range of donors remains vital [209]. The current ESPEN needs to work collaboratively with major international funders as well as with other stakeholders to maintain the achievements of previous programs, and to offer both technical and financial support to eliminate onchocerciasis [74]. Governments of endemic countries and their NGO partners need to take full ownership of their national elimination programs by allocating and mobilizing adequate resources for the intended goal. A strong commitment is compulsory from volunteer CDDs, frontline health workers, and beneficiary communities to reach the last mile.

\section{Conclusions}

Great strides have been made over the past decades to control and eliminate onchocerciasis in Africa through devoted regional programs, which have been largely successful in most endemic countries. Elimination of onchocerciasis as a disease has also been achieved in limited localities in Africa, and this has provided optimism for a complete elimination of the disease from the rest of Africa by 2025. However, there are numerous challenges that hinder the existing efforts to eliminate onchocerciasis from Africa. The major challenges include an incomplete mapping of all transmission zones, co-endemicity of onchocerciasis and loiasis, possible emergence of ivermectin resistance, uncoordinated cross-border elimination efforts, conflict and civil unrest, suboptimal program implementation, and technical and financial challenges.

It is, therefore, recommended that the impact of those and other challenges be identified in each national onchocerciasis elimination program, and appropriate measures be implemented to accelerate the elimination of onchocerciasis. Some recommendations to overcome the aforementioned challenges and suggested actions to accelerate the elimination of onchocerciasis by 2025 include: a need for complete disease elimination mapping, a need for collaborative elimination activities between national programs, a need for a different drug distribution approach in conflict-affected areas, a need for routine monitoring and evaluation of MDA programs, a need for implementing ATSs in areas with elimination anticipated beyond 2025, and a need for strong partnerships and continued funding.

\section{Additional file}

Additional file 1: Multilingual abstracts in the five official working languages of the United Nations. (PDF $374 \mathrm{~kb}$ )

\section{Abbreviations}

APOC: African Programme for Onchocerciasis Control; ATS: Alternative treatment strategy; CAR: Central African Republic; CDD: Community drug distributor; CDTI: Community-directed treatment with ivermectin; DRC: Democratic Republic of the Congo; ESPEN: Expanded Special Project for Elimination of Neglected Tropical Diseases; MDA: Mass drug administration; 
NGO: Non-governmental organization; NTD: Neglected tropical disease; OCP: Onchocerciasis Control Programme in West Africa; PCR: Polymerase chain reaction; PTS: Post-treatment surveillance; WHO: World Health Organization

\section{Acknowledgments}

We are grateful to the reviewers for their constructive comments and critical suggestions.

\section{Authors' contributions}

GG wrote the initial draft. GG, ZM, DY, and AH critically revised the initial draft and approved the final paper for publication.

\section{Funding}

No funding

\section{Availability of data and materials}

Not applicable

\section{Ethics approval and consent to participate}

Not applicable

\section{Consent for publication}

Not applicable

\section{Competing interests}

The authors declare that they have no competing interests.

\section{Author details}

${ }^{1}$ School of Medical Laboratory Sciences, Institute of Health Sciences, Jimma University, P.O. Box 378, Jimma, Ethiopia. ${ }^{2}$ College of Veterinary Medicine, Samara University, Samara, Ethiopia. ${ }^{3}$ Tropical and Infectious Diseases Research Center, Jimma University, Jimma, Ethiopia. ${ }^{4}$ Department of Microbiology, Immunology, and Parasitology, School of Medicine, College of Health Sciences, Addis Ababa University, Addis Ababa, Ethiopia.

Received: 23 December 2018 Accepted: 10 June 2019

\section{Published online: 04 July 2019}

\section{References}

1. Noma M, Zouré $H G$, Tekle AH, Enyong PA, Nwoke BE, Remme JH. The geographic distribution of onchocerciasis in the 20 participating countries of the African Programme for Onchocerciasis Control: (1) priority areas for ivermectin treatment. Parasit Vectors. 2014;7(1):325

2. Taylor HR, Duke BO, Munoz B. The selection of communities for treatment of onchocerciasis with ivermectin. Trop Med Parasitol. 1992;43(4):267-70.

3. Ozoh GA, Murdoch ME, Bissek AC, Hagan M, Ogbuagu K, Shamad M, et al. The African Programme for Onchocerciasis Control: impact on onchocercal skin disease. Tropical Med Int Health. 2011;16(7):875-83.

4. BA B, Amazigo U. Onchocerciasis. In: Gyapong J, Boatin B, editors. Neglected Tropical Diseases-sub-Saharan Africa. Springer International Publishing. Switzerland; 2016. p. 87-112

5. Uniting to Combat Neglected Tropical Diseases. River blindness (onchocerciasis). https://unitingtocombatntds.org/ntds/onchocerciasis/. Accessed 30 Jan 2019

6. Basáñez MG, Sébastien DS, Churcher TS, Breitling LP, Little MP, Boussinesd M. River blindness: a success story under threat? PLoS Med. 2006;3(9):e371.

7. Hotez PJ, Kamath A. Neglected tropical diseases in sub-Saharan Africa: review of their prevalence, distribution, and disease burden. PLoS Negl Trop Dis. 2009;3(8):e412.

8. Crump A, Morel CM, Omura S. The onchocerciasis chronicle: from the beginning to the end? Trends Parasitol. 2012;28(7):280-8

9. Kim YE, Remme JH, Steinmann P, Stolk WA, Roungou JB, Tediosi F. Control, elimination, and eradication of river blindness: scenarios, timelines, and ivermectin treatment needs in Africa. PLoS Negl Trop Dis. 2015;9(4):e0003664.

10. Hopkins A. Onchocerciasis then and now: achievements, priorities and challenges. Community Eye Health. 2017:30(100):92.

11. De Sole G, Baker R, Dadzie KY, Giese J, Guillet P, Keita FM, et al. Onchocerciasis distribution and severity in five West African countries. Bull World Health Organ. 1991;69(6):689.
12. Murdoch ME, Asuzu MC, Hagan M, Makunde WH, Ngoumou P, Ogbuagu KF, et al. Onchocerciasis: the clinical and epidemiological burden of skin disease in Africa. Ann Trop Med Parasitol. 2002;96(3):283-96.

13. Koroma JB, Sesay S, Conteh A, Koudou B, Paye J, Bah M, et al. Impact of five annual rounds of mass drug administration with ivermectin on onchocerciasis in Sierra Leone. Infect Dis Poverty. 2018;7:30.

14. Little MP, Breitling LP, Basáñez MG, Alley ES, Boatin BA. Association between microfilarial load and excess mortality in onchocerciasis: an epidemiological study. Lancet. 2004;363(9420):1514-21.

15. Hopkins A, Boatin BA. Onchocerciasis. In: Selendy JMH, editor. Water and Sanitation-Related Diseases and the Environment: Challenges, Interventions, and Preventive Measures. 1st ed: Wiley-Blackwell: John Wiley \& Sons, Inc. Hoboken; 2011. p. 133-49.

16. Prost $\mathrm{A}$. The burden of blindness in adult males in the savanna villages of West Africa exposed to onchocerciasis. Trans R Soc Trop Med Hyg. 1986:80(4):525-7.

17. Pion SD, Kamgno J, Demanga-Ngangue, Boussinesq M. Excess mortality associated with blindness in the onchocerciasis focus of the Mbam Valley, Cameroon. Ann Trop Med Parasitol. 2002;96(2):181-9.

18. Boussinesq M, Pion SD, Kamgno J. Relationship between onchocerciasis and epilepsy: a matched case-control study in the Mbam Valley, Republic of Cameroon. Trans R Soc Trop Med Hyg. 2002;96(5):537-41.

19. Kaiser C, Pion SD, Boussinesq M. Case-control studies on the relationship between onchocerciasis and epilepsy: systematic review and meta-analysis. PLoS Negl Trop Dis. 2013;7(3):e2147.

20. Colebunders R, Titulaer MJ. Nodding syndrome: Preventable and treatable. Sci Transl Med. 2017;9(377):1-3.

21. Vlassoff C, Weiss M, Ovuga EB, Eneanya C, Nwel PT, Babalola SS, et al. Gender and the stigma of onchocercal skin disease in Africa. Soc Sci Med. 2000;50(10):1353-68.

22. Prost A, Vaugelade J. Excess mortality among blind persons in the West African savannah zone. Bull World Health Organ. 1981;59(5):773-6.

23. World Bank. World Bank development report 1993: Investing in health. New York: Oxford University Press. World Bank; 1993. https://openknowledge. worldbank.org/handle/10986/5976. Accessed 24 July 2018

24. Benton B. Economic Impact of Onchocerciasis Control through APOC: an Overview. Ann Trop Med Parasitol. 1998:92(suppl 1):S33-9.

25. Oladepo O, Brieger WR, Otusanya S, Kale OO, Offiong S, Titiloye M. Farm land size and onchocerciasis status of peasant farmers in south-western Nigeria. Tropical Med Int Health. 1997;2(4):334-40.

26. Etya'ale D. Vision 2020: Update on onchocerciasis. Community Eye Health. 2001;14(38):19.

27. Waters HR, Rehwinkel JA, Burnham G. Economic evaluation of Mectizan ${ }^{\circledR}$ distribution. Tropical Med Int Health. 2004;9(4):A16-25.

28. Tekle AH, Elhassan E, Isiyaku S, Amazigo UV, Bush S, Noma M, et al. Impact of long-term treatment of onchocerciasis with ivermectin in Kaduna State, Nigeria: first evidence of the potential for elimination in the operational area of the African Programme for Onchocerciasis Control. Parasit Vectors. 2012;5(1):28.

29. Boatin B. The onchocerciasis control programme in West Africa (OCP). Ann Trop Med Parasitol. 2008;102(suppl):13-7.

30. Tekle AH, Zouré HG, Noma M, Boussinesq M, Coffeng LE, Stolk WA, et al. Progress towards onchocerciasis elimination in the participating countries of the African Programme for Onchocerciasis Control: epidemiological evaluation results. Infect Dis Poverty. 2016;5(1):66.

31. World Health Organization/African programme for onchocerciasis Control. Guidelines for revising ivermectin treatment boundaries within the context of onchocerciasis elimination. World Health Organization; WHO/MG/15.21. http://www.who.int/apoc/ATS_Report_Annex1_APOC_Guidelines_for_ revising_IVM_Tx_boundaries.pdf. Accessed 09 Oct 2018.

32. The Carter Center. River Blindness Transmission Interrupted in cross border Metema Focus, Amhara Regional State, Ethiopia. https://www.cartercenter org/resources/pdfs/news/health_publications/river_blindness/rb-ethiopiafmoh-press-release.pdf. Accessed 30 Jan 2019

33. Diawara L, Traoré MO, Badji A, Bissan Y, Doumbia K, Goita SF, et al. Feasibility of onchocerciasis elimination with ivermectin treatment in endemic foci in Africa: first evidence from studies in Mali and Senegal. PLoS Negl Trop Dis. 2009;3(7):e497.

34. Katabarwa MN, Walsh F, Habomugisha P, Lakwo TL, Agunyo S, Oguttu DW, et al. Transmission of onchocerciasis in Wadelai focus of north western Uganda has been interrupted and the disease eliminated. J Parasitol Res. 2012;2012:748540. 
35. Traoré MO, Sarr MD, Badji A, Bissan Y, Diawara L, Doumbia K, et al. Proof-ofprinciple of onchocerciasis elimination with ivermectin treatment in endemic foci in Africa: final results of a study in Mali and Senegal. PLoS Negl Trop Dis. 2012;6(9):e1825.

36. Lakwo TL, Garms R, Rubaale T, Katabarwa M, Walsh F, Habomugisha P, et al. The disappearance of onchocerciasis from the Itwara focus, western Uganda after elimination of the vector Simulium neavei and 19 years of annual ivermectin treatments. Acta Trop. 2013;126(3):218-21.

37. Evans DS, Alphonsus K, Umaru J, Eigege A, Miri E, Mafuyai $H$, et al. Status of Onchocerciasis transmission after more than a decade of mass drug administration for onchocerciasis and lymphatic filariasis elimination in central Nigeria: challenges in coordinating the stop MDA decision. PLoS Negl Trop Dis. 2014;8(9):e3113.

38. Zarroug IM, Hashim K, EIMubark WA, Shumo ZA, Salih KA, EINojomi NA, et al. The first confirmed elimination of an onchocerciasis focus in Africa: Abu Hamed, Sudan. Am J Trop Med Hyg. 2016;95(5):1037-40.

39. Herrador Z, Garcia B, Ncogo P, Perteguer MJ, Rubio JM, Rivas E, et al Interruption of onchocerciasis transmission in Bioko Island: Accelerating the movement from control to elimination in Equatorial Guinea. PLoS Negl Trop Dis. 2018;12(5):e0006471.

40. World Health Organization. Accelerating work to overcome the global impact of neglected tropical diseases: a roadmap for implementation. Geneva: World Health Organization; WHO/HTM/NTD/PCT/20121; 2012. https://www.who.int/neglected_diseases/NTD_RoadMap_2012_Fullversion. pdf. Accessed 13 May 2018

41. World Health Organization/African Programme for Onchocerciasis Control. In: 18th Session of the Joint Action Forum. Bujumbura, Burundi. Final Communique. 2012. https://www.who.int/apoc/about/structure/jaf/Final_ Communique_JAF_18_English_final_with_annexes.pdf?ua=1. Accessed 13 May 2018.

42. London Declaration on neglected tropical diseases. 2012. Uniting to Combat NTDs. https://unitingtocombatntds.org/london-declarationneglected-tropical-diseases/. Accessed 14 Oct 2018.

43. World Health Organization. Guidelines for stopping mass drug administration and verifying elimination of human onchocerciasis: criteria and procedures. 2016,WHO/HTM/NTD/PCT/2016.1. http://apps.who.Int/iris/ bitstream/10665/204180/1/9789241510011_eng.pdf. Accessed 13 May 2018.

44. Higazi TB, Geary TG, MacKenzie CD. Chemotherapy in the treatment, control, and elimination of human onchocerciasis. Res Rep Trop Med. 2014;5:77-93.

45. United States Agency for International Development (USAID). USAID Neglected Tropical Disease Program 2016 Evaluation https://www. neglecteddiseases.gov/docs/default-source/ntd-documents/usaid-neglectedtropical-disease-program-2016-evaluation.pdf. Accessed 14 Nov 2018.

46. Boussinesq M, Fobi G, Kuesel AC. Alternative treatment strategies to accelerate the elimination of onchocerciasis. Int Health. 2018;10(suppl 1):i40-8.

47. Gustavsen KM, Colatrella BD, McCoy T. For as Long as Necessary: Examining 30 years of MSD's Focus on Achieving Elimination of Onchocerciasis and Lymphatic Filariasis. Int Health. 2018;10(suppl 1):i3-6.

48. Lawrence J, Sodahlon YK. Onchocerciasis: the beginning of the end. Int Health. 2018;10(suppl 1):i1-2.

49. Verver S, Walker M, Kim YE, Fobi G, Tekle AH, Zouré HG, et al. How can onchocerciasis elimination in Africa be accelerated? Modeling the impact of increased ivermectin treatment frequency and complementary vector control. Clin Infect Dis. 2018;66(suppl 4):S267-74.

50. C Campbell W. History of avermectin and ivermectin, with notes on the history of other macrocyclic lactone antiparasitic agents. Curr Pharm Biotechnol. 2012;13(6):853-65.

51. World Health Organization. Onchocerciasis Control Programme (OCP). http://www.who.int/blindness/partnerships/onchocerciasis_OCP/en/. Accessed 25 July 2018.

52. Fobi G, Yameogo L, Noma M, Aholou Y, Koroma JB, Zouré HM, et al. Managing the fight against onchocerciasis in Africa: APOC experience. PLoS Negl Trop Dis. 2015;9(5):e0003542

53. Roungou JB, Yameogo L, Mwikisa C, Boakye DA, Bundy DA. 40 Years of the APOC Partnership. PLoS Negl Trop Dis. 2015;9(5):e0003562.

54. Remme JHF. The Global Burden of Onchocerciasis in 1990. Geneva: World Health Organization; 2004. http://www.who.int/healthinfo/global_burden_ disease/Onchocerciasis\%201990.pdf. Accessed 28 July 2018

55. O'Hanlon SJ, Slater HC, Cheke RA, Boatin BA, Coffeng LE, Pion SD, et al. Model-Based Geostatistical Mapping of the Prevalence of Onchocerca volvulus in West Africa. PLoS Negl Trop Dis. 2016;10(1):e0004328.
56. Amazigo UV, Brieger WR, Katabarwa M, Akogun O, Ntep M, Boatin B, et al. The challenges of community-directed treatment with ivermectin (CDTI) within the African Programme for Onchocerciasis Control (APOC). Ann Trop Med Parasitol. 2002;96(sup1):S41-58.

57. Amazigo U. The African programme for onchocerciasis control (APOC). Ann Trop Med Parasitol. 2008;102(sup1):19-22.

58. Cupp EW, Sauerbrey M, Richards F. Elimination of human onchocerciasis: history of progress and current feasibility using ivermectin (Mectizan ${ }^{\oplus}$ ) monotherapy. Acta Trop. 2011;120:S100-8.

59. Coffeng LE, Stolk WA, Zoure HG, Veerman JL, Agblewonu KB, Murdoch ME, et al. African Programme For Onchocerciasis Control 1995-2015: modelestimated health impact and cost. PLoS Negl Trop Dis. 2013;7(1):e2032.

60. Coffeng LE, Stolk WA, Zoure HG, Veerman JL, Agblewonu KB, Murdoch ME, et al. African programme for onchocerciasis control 1995-2015: updated health impact estimates based on new disability weights. PLoS Negl Trop Dis. 2014;8(6):e2759.

61. Turner HC, Walker M, Churcher TS, Basáñez MG. Modelling the impact of ivermectin on River Blindness and its burden of morbidity and mortality in African Savannah: Epi Oncho projections. Parasit Vectors. 2014;7(1):241.

62. Kuesel AC. Research for new drugs for elimination of onchocerciasis in Africa. Int J Parasitol Drugs Drug Resist. 2016;6(3):272-86.

63. World Health Organization. Onchocerciasis. http://www.who.int/ mediacentre/factsheets/fs374/en/. Accessed 25 July 2018.

64. Samba EM. The onchocerciasis control programme in Africa. Geneva: World Health Organization; 1994.

65. Aehyung K, Benton B. Cost-benefit analysis of the Onchocerciasis Control Program (OCP). The World Bank. Washington; 1995. p. 1-18.

66. Boatin B, Molyneux DH, Hougard JM, Christensen OW, Alley ES, Yameogo L, et al. Patterns of epidemiology and control of onchocerciasis in West Africa. Jelminthol. 1997;71(2):91-101.

67. Richards FO Jr, Boatin B, Sauerbrey M, Sékétéli A. Control of onchocerciasis today: status and challenges. Trends Parasitol. 2001;17(12):558-63.

68. Dadzie $Y$, Neira M, Hopkins D. Final report of the Conference on the eradicability of Onchocerciasis. Filaria J. 2003;2(1):2.

69. Molyneux DH. Onchocerciasis control and elimination: coming of age in resource-constrained health systems. Trends Parasitol. 2005;21(11):525-9.

70. Bush S. Ngorok J. Elimination of onchocerciasis; Ten-year strategic fast tracking plan in Sight savers supported countries 2011-2021. West Sussex: Sight savers; 2011. http://www.sightsavers.org/wp-content/uploads/2017/ 11/19377_0303_SS-Oncho-Report-Lowres.pdf. Accessed 16 Oct 2018

71. World Health Organization/African Programme for Onchocerciasis Control. Programme for the Elimination of Neglected Diseases in Africa (PENDA). Strategic Plan of Action and Indicative Budget 2016-2025. Ouagadougou. African Programme for Onchocerciasis Control, JAF19.8, 2013. https://www. who.int/apoc/en_apoc_strategic_plan_2013_ok.pdf. Accessed 1 Dec 2018.

72. World Health Organization. African Programme for Onchocerciasis Control (APOC). http://www.who.int/apoc/onchocerciasis/ocp/en/. Accessed 25 July 2018.

73. Hopkins AD. Neglected tropical diseases in Africa: a new paradigm. Int Health. 2016;8(suppl 1):i28-33.

74. Colebunders R, Basáñez MG, Siling K, Post RJ, Rotsaert A, Mmbando B, et al. From river blindness control to elimination: bridge over troubled water. Infect Dis Poverty. 2018;7(1):21.

75. World Health Organization/African Programme for Onchocerciasis Control. Conceptual and operational framework of onchocerciasis elimination with ivermectin treatment. World Health Organization; WHO/APOC/MG/10.1. 2010. https://www.who.int/apoc/oncho_elimination_report_english.pdf. Accessed 16 Oct 2018.

76. Medscape. Onchocerciasis (River Blindness) Guidelines. https://emedicine. medscape.com/article/224309-guidelines. Accessed 16 Nov 2018.

77. Ngoumou P, Walsh JF, Mace JM. A rapid mapping technique for the prevalence and distribution of onchocerciasis: a Cameroon case study. Ann Trop Med Parasitol. 1994;88(5):463-74

78. Noma M, Nwoke BE, Nutall I, Tambala PA, Enyong P, Namsenmo A, et al. Rapid epidemiological mapping of onchocerciasis (REMO): its application by the African Programme for Onchocerciasis Control (APOC). Ann Trop Med Parasitol. 2002;96(sup1):S29-39.

79. Zouré HG, Noma M, Tekle AH, Amazigo UV, Diggle PJ, Giorgi E, et al. The geographic distribution of onchocerciasis in the 20 participating countries of the African Programme for Onchocerciasis Control: (2) precontrol endemicity levels and estimated number infected. Parasit Vectors. 2014;7(1):326 
80. World Health Organization. Rapid epidemiological mapping of onchocerciasis (REMO). http://www.who.int/apoc/cdti/remo/en/. Accessed 11 Oct 2018.

81. Boatin BA, Richards FO Jr. Control of onchocerciasis. Adv Parasitol. 2006;61: 349-94.

82. World Health Organization. Report of the $1^{\text {st }}$ meeting of the $\mathrm{WHO}$ onchocerciasis technical advisory subgroup. Varembé Conference Centre, Geneva, Switzerland, 10-12 October 2017. World Health Organization. 2018 https://apps.who.int/iris/bitstream/handle/10665/273705/WHO-CDS-NTDPCT-2018.05-eng.pdf. Accessed 30 Jan 2019

83. Coffeng LE, Pion SD, O'Hanlon S, Cousens S, Abiose AO, Fischer PU, et al. Onchocerciasis: the pre-control association between prevalence of palpable nodules and skin microfilariae. PLoS Negl Trop Dis. 2013;7(4):e2168.

84. Katabarwa MN, Eyamba A, Chouaibou M, Enyong P, Kuété T, Yaya S, et al. Does onchocerciasis transmission take place in hypoendemic areas? A study from the North Region of Cameroon. Tropical Med Int Health. 2010;15(5):645-52.

85. Kelly-Hope LA, Unnasch TR, Stanton MC, Molyneux DH. Hypo-endemic onchocerciasis hotspots: defining areas of high risk through micro-mapping and environmental delineation. Infect Dis Poverty. 2015;4(1):36.

86. Boakye D, Tallant J, Adjami A, Moussa S, Tekle A, Robalo M, et al. Refocusing vector assessment towards the elimination of onchocerciasis from Africa: a review of the current status in selected countries. Int Health. 2018;10(suppl 1):i27-32.

87. Atsame J, Barbre KA, Renneker K, Robello MP, Zoure H. (Abstract) Filariasis in Gabon: empiric assessments refine distribution and treatment strategies for onchocerciasis and loiasis. Am J Trop Med Hyg. 2016;95(Suppl 5):17.

88. Cantey PT, Roy SL, Boakye D, Mwingira U, Ottesen EA, Hopkins AD, et al. Transitioning from river blindness control to elimination: steps toward stopping treatment. Int Health. 2018;10(suppl 1):i7-13.

89. Neglected Tropical Diseases Support Center. Making a Case for Onchocerciasis Elimination Mapping: An Interview with Philip Downs and Charles Mackenzie. 2018. https://www.ntdsupport.org/cor-ntd/blog/makingcase-onchocerciasis-elimination-mapping-interview-philip-downs-andcharles. Accessed 12 Oct 2018

90. Mackenzie CD, Homeida MM, Hopkins AD, Lawrence JC. Elimination of onchocerciasis from Africa: possible? Trends Parasitol. 2012;28(1):16-22.

91. Lakwo T, Ukety T, Bakajika D, Tukahebwa E, Awaca P, Amazigo U. Crossborder collaboration in onchocerciasis elimination in Uganda: progress, challenges and opportunities from 2008 to 2013. Glob Health. 2018;14(1):16.

92. Zouré HG, Wanji S, Noma M, Amazigo UV, Diggle PJ, Tekle AH, et al. The geographic distribution of Loa loa in Africa: Results of large-scale implementation of the Rapid Assessment Procedure for Loiasis (RAPLOA). PLoS Negl Trop Dis. 2011;5(6):e1210.

93. Gardon J, Gardon-Wendel N, Kamgno J, Chippaux JP, Boussinesq M. Serious reactions after mass treatment of onchocerciasis with ivermectin in an area endemic for Loa loa infection. Lancet. 1997;350(9070):18-22.

94. Boussinesq M, Gardon J, Gardon-Wendel N, Kamgno J, Ngoumou P, Chippaux JP. Three probable cases of Loa loa encephalopathy following ivermectin treatment for onchocerciasis. Am J Trop Med Hyg. 1998;58(4):461-9.

95. Boussinesq M. Loiasis. Ann Trop Med Parasitol. 2006;100(8):715-31.

96. Lawrence J, Sodahlon YK, Ogoussan KT, Hopkins AD. Growth, challenges, and solutions over 25 years of Mectizan ${ }^{\oplus}$ and the impact on onchocerciasis control. PLoS Negl Trop Dis. 2015;9(5):e0003507.

97. Addiss DG, Rheingans R, Twum-Danso NA, Richards FO. A framework for decision-making for mass distribution of Mectizan ${ }^{\circledR}$ in areas endemic for Loa loa. Filaria J. 2003;2(1):S9

98. Wanji S, Tendongfor N, Esum M, Yundze SS, Taylor MJ, Enyong P. Combined utilisation of rapid assessment procedures for loiasis (RAPLOA) and onchocerciasis (REA) in rain forest villages of Cameroon. Filaria J. 2005;4(1):2.

99. Kamgno J, Nana-Djeunga HC, Pion SD, Chesnais CB, Klion AD, Mackenzie $C D$, et al. Boussinesq M. Operationalization of the test and not treat strategy to accelerate the elimination of onchocerciasis and lymphatic filariasis in Central Africa. Int Health. 2018;10(suppl 1):i49-53.

100. Hoerauf A, Pfarr K, Mand S, Debrah AY, Specht S. Filariasis in Africa-treatment challenges and prospects. Clin Microbiol Infect. 2011; 17(7):977-85.

101. Cupp EW, Mackenzie CD, Unnasch TR. Importance of ivermectin to human onchocerciasis: past, present and the future. Res Rep Trop Med. 2011;2:81-92.

102. Ogoussan KT, Hopkins A. Mectizan ${ }^{\oplus}$ procurement and delivery for onchocerciasis mass drug administration programmes. Acta Trop. 2011;120: s173-6.
103. Duke BO, Zea-Flores G, Castro J, Cupp EW, Munoz B. Comparison of the effects of a single dose and of four six-monthly doses of ivermectin on adult Onchocerca volvulus. Am J Trop Med Hyg. 1991;45(1):132-7.

104. Walker M, Pion SD, Fang H, Gardon J, Kamgno J, Basáñez MG, et al. Macrofilaricidal efficacy of repeated doses of ivermectin for the treatment of river blindness. Clin Infect Dis. 2017;65(12):2026-34.

105. Cupp EW, Duke BO, Mackenzie CD, Guzmán JR, Vieira JC, Mendez-Galvan J, et al. The effects of long-term community level treatment with ivermectin $\left(\right.$ Mectizan $\left.^{\oplus}\right)$ on adult Onchocerca volvulus in Latin America. Am J Trop Med Hyg. 2004;71(5):602-7.

106. Osei-Atweneboana MY, Eng JK, Boakye DA, Gyapong JO, Prichard RK. Prevalence and intensity of Onchocerca volvulus infection and efficacy of ivermectin in endemic communities in Ghana: a two-phase epidemiological study. Lancet. 2007;369(9578):2021-9.

107. Churcher TS, Pion SD, Osei-Atweneboana MY, Prichard RK, Awadzi K, Boussinesq $M$, et al. Identifying sub-optimal responses to ivermectin in the treatment of River Blindness. Proc Natl Acad Sci. 2009. https://doi.org/10. 1073/pnas.0906176106

108. Osei-Atweneboana MY, Awadzi K, Attah SK, Boakye DA, Gyapong JO, Prichard RK. Phenotypic evidence of emerging ivermectin resistance in Onchocerca volvulus. PLoS Negl Trop Dis. 2011;5(3):e998.

109. Lamberton PH, Cheke RA, Winskill P, Tirados I, Walker M, Osei-Atweneboana MY, et al. Onchocerciasis transmission in Ghana: persistence under different control strategies and the role of the simuliid vectors. PLoS Negl Trop Dis. 2015;9(4):e0003688.

110. Pion SD, Nana-Djeunga HC, Kamgno J, Tendongfor N, Wanji S, Njiokou F, et al. Dynamics of Onchocerca volvulus microfilarial densities after ivermectin treatment in an ivermectin-naive and a multiply treated population from Cameroon. PLoS Negl Trop Dis. 2013;7(2):e2084.

111. Nana-Djeunga HC, Bourguinat C, Pion SD, Bopda J, Kengne-Ouafo JA, Njiokou F, et al. Reproductive status of Onchocerca volvulus after ivermectin treatment in an ivermectin-naive and a frequently treated population from Cameroon. PLoS Negl Trop Dis. 2014;8(4):e2824.

112. Ardelli BF, Prichard RK. Identification of variant ABC-transporter genes among Onchocerca volvulus collected from ivermectin-treated and untreated patients in Ghana, West Africa. Ann Trop Med Parasitol. 2004; 98(4):371-84.

113. Ardelli BF, Guerriero SB, Prichard RK. Genomic organization and effects of ivermectin selection on Onchocerca volvulus P-glycoprotein. Mol Biochem Parasitol. 2005;143(1):58-66.

114. Eng JK, Prichard RK. A comparison of genetic polymorphism in populations of Onchocerca volvulus from untreated-and ivermectin-treated patients. Mol Biochem Parasitol. 2005;142(2):193-202.

115. Ardelli BF, Guerriero SB, Prichard RK. Ivermectin imposes selection pressure on P-glycoprotein from Onchocerca volvulus: linkage disequilibrium and genotype diversity. Parasitol. 2006;132(3):375-86.

116. Eng JK, Blackhall WJ, Osei-Atweneboana MY, Bourguinat C, Galazzo D, Beech $\mathrm{RN}$, et al. Ivermectin selection on $\beta$-tubulin: Evidence in Onchocerca volvulus and Haemonchus contortus. Mol Biochem Parasitol. 2006;150(2):229-35.

117. Ardelli BF, Prichard RK. Reduced genetic variation of an Onchocerca volvulus $A B C$ transporter gene following treatment with ivermectin. Trans $R$ Soc Trop Med Hyg. 2007;101(12):1223-32.

118. Bourguinat C, Pion SD, Kamgno J, Gardon J, Duke BO, Boussinesq M, et al. Genetic selection of low fertile Onchocerca volvulus by ivermectin treatment. PLoS Negl Trop Dis. 2007;1(1):e72.

119. Nana-Djeunga H, Bourguinat C, Pion SD, Kamgno J, Gardon J, Njiokou F, et al. Single nucleotide polymorphisms in $\beta$-tubulin selected in Onchocerca volvulus following repeated ivermectin treatment: possible indication of resistance selection. Mol Biochem Parasitol. 2012;185(1):10-8.

120. Osei-Atweneboana MY, Boakye DA, Awadzi K, Gyapong JO, Prichard RK. Genotypic analysis of $\beta$-tubulin in Onchocerca volvulus from communities and individuals showing poor parasitological response to ivermectin treatment. Int J Parasitol Drugs Drug Resist. 2012;2:20-8.

121. Doyle SR, Bourguinat C, Nana-Djeunga HC, Kengne-Ouafo JA, Pion SD, Bopda J, Kamgno J, Wanji S, Che H, Kuesel AC, Walker M. Genome-wide analysis of ivermectin response by Onchocerca volvulus reveals that genetic drift and soft selective sweeps contribute to loss of drug sensitivity. PLoS Negl Trop Dis. 2017;11(7):e0005816.

122. Kudzi W, Dodoo AN, Mills JJ. Genetic polymorphisms in MDR1, CYP3A4 and CYP3A5 genes in a Ghanaian population: a plausible explanation for altered metabolism of ivermectin in humans? BMC Med Genet. 2010;11(1):111. 
123. Gustavsen K, Sodahlon Y, Bush S. Cross-border collaboration for neglected tropical disease efforts - Lessons learned from onchocerciasis control and elimination in the Mano River Union (West Africa). Glob Health. 2016;12(1):44.

124. allafrica.com. Uganda: Joint Effort to Eliminate River Blindness Bearing Fruit for Uganda. allafrica.com/The East African. 2018. https:/allafrica.com/stories/ 201808160423.html. Accessed on 02 Oct 2018.

125. Outbreak News Today. Cross-border transmissions from Democratic Republic of Congo, South Sudan stall Ugandan bid to eliminate river blindness. Outbreak news today. 2018. http://outbreaknewstoday.com/crossborder-transmissions-drc-south-sudan-stall-ugandan-bid-eliminate-riverblindness-32660/. Accessed on 02 Oct 2018.

126. Bush S, Sodahlon Y, Downs P, Mackenzie CD. Cross-border issues: an important component of onchocerciasis elimination programmes. Int Health. 2018;10(suppl 1):i54-9.

127. Dadzie Y, Amazigo UV, Boatin BA, Sékétéli A. Is onchocerciasis elimination in Africa feasible by 2025: a perspective based on lessons learnt from the African control programmes. Infect Dis Poverty. 2018;7(1):63.

128. Nikièma AS, Koala L, Post RJ, Paré $A B$, Kafando CM, Drabo F, et al. Onchocerciasis prevalence, human migration and risks for onchocerciasis elimination in the Upper Mouhoun, Nakambé and Nazinon river basins in Burkina Faso. Acta Trop. 2018;185:176-82.

129. Garms R, Walsh JF, Davies JB. Studies on the reinvasion of the Onchocerciasis Control Programme in the Volta River Basin by Simulium damnosum s/ with emphasis on the south-western areas. Tropenmed Parasitol. 1979:30(3):345-62.

130. Baker RH, Guillet P, Seketeli A, Poudiougo P, Boakye D, Wilson MD, et al. Progress in controlling the reinvasion of windborne vectors into the western area of the Onchocerciasis Control Programme in West Africa. Philos Trans R Soc Lond B. 1990;328(1251):731-50.

131. World Health Organization. Informal consultation on elimination of onchocerciasis transmission with current tools in Africa-"shrinking the map". Ouagadougou, Burkina Faso. African Programme for Onchocerciasis Control; 2009. https://mectizan.org/wp-content/uploads/2017/03/Report-of-Informalconsultation-on-elimination-of-oncho-transmission-with-current-tools-inAfrica.pdf. Accessed 02 Oct 2018.

132. Koala L, Nikiema A, Post RJ, Paré AB, Kafando CM, Drabo F, et al. Recrudescence of onchocerciasis in the Comoé valley in Southwest Burkina Faso. Acta Trop. 2017;166:96-105.

133. Komlan K, Vossberg PS, Gantin RG, Solim T, Korbmacher F, Banla M, et al. Onchocerca volvulus infection and serological prevalence, ocular onchocerciasis and parasite transmission in northern and central Togo after decades of Simulium damnosum sl vector control and mass drug administration of ivermectin. PLoS Negl Trop Dis. 2018;12(3):e0006312.

134. The Guardian. River blindness: from disease control to elimination. The Guardian. Monday 17 December 2012. https://www.theguardian.com/ global-development-professionals-network/2012/dec/17/river-blindnessdisease-africa. Accessed 03 Oct 2018.

135. Makenga Bof JC, Maketa V, Bakajika DK, Ntumba F, Mpunga D, Murdoch ME, et al. Onchocerciasis control in the Democratic Republic of Congo (DRC): challenges in a post-war environment. Tropical Med Int Health. 2015;20(1):48-62.

136. World Health Organization. Sustaining the drive to overcome the global impact of neglected tropical diseases: World Health Organization. 2013. Geneva; 2013. p. 1-138.

137. Jacobson J, Bush S. Neglected Tropical Diseases, Neglected Communities, and Conflict: How Do We Leave No One Behind? Trends Parasitol. 2018; 34(3):175-7.

138. Brieger WR, Okeibunor JC, Abiose AO, Wanji S, Elhassan E, Ndyomugyenyi R, et al. Compliance with eight years of annual ivermectin treatment of onchocerciasis in Cameroon and Nigeria. Parasit Vectors. 2011:4(1):1.

139. World Health Organization. Report of consultative meetings on strategic options and alternative treatment strategies for accelerating onchocerciasis elimination in Africa. WHO/MG/15/20. Geneva: World Health Organization; 2015. https:// www.who.int/apoc/ATS_Report_2015.12.pdf. Accessed 2 Dec 2018.

140. World Health Organization. Monitoring drug coverage for preventive chemotherapy. WHO/HTM/NTD/PCT/2010.1. Geneva: World Health Organization; 2010. http://apps.who.int/iris/bitstream/handle/10665/44400/ ?sequence=1. Accessed 1 Dec 2018

141. Bockarie MJ, Kelly-Hope LA, Rebollo M, Molyneux DH. Preventive chemotherapy as a strategy for elimination of neglected tropical parasitic diseases: endgame challenges. Philos Trans R Soc B. 2013;368(1623): 20120144.
142. Coffeng LE, Stolk WA, Hoerauf A, Habbema D, Bakker R, Hopkins AD, et al. Elimination of African onchocerciasis: modeling the impact of increasing the frequency of ivermectin mass treatment. PLoS One. 2014;9(12):e115886.

143. World Health Organization. African Programme for onchocerciasis control-report on task force meeting, July 2008. Wkly Epidemiol Rec. 2008; 83(34):307-12.

144. World Health Organization. African Programme for onchocerciasis control-report of the sixth meeting of national task forces, October 2009. Wkly Epidemiol Rec. 2010;85(04):23-8.

145. World Health Organization. Meeting of the national onchocerciasis task forces, September 2010. Wkly Epidemiol Rec. 2010;85(48):473-479.

146. World Health Organization. African Programme for Onchocerciasis Control: meeting of national task forces, September 2011. Wkly Epidemiol Rec. 2011 ; 86(48):541-9.

147. World Health Organization. African Programme for Onchocerciasis Control: meeting of national onchocerciasis task forces, September 2012. Wkly Epidemiol Rec. 2012;87(49-50):494-502.

148. World Health Organization. African Programme for Onchocerciasis Control: meeting of national onchocerciasis task forces. Wkly Epidemiol Rec. 2013; 88(50):533-44

149. World Health Organization. African Programme for Onchocerciasis Control: progress report, 2013-2014. Wkly Epidemiol Rec. 2014;89(49):551-60.

150. World Health Organization. African Programme for Onchocerciasis Control: progress report, 2014-2015. Wkly Epidemiol Rec. 2015;90(49):661-74.

151. World Health Organization. Progress report on the elimination of human onchocerciasis, 2015-2016. Wkly Epidemiol Rec. 2016;91(43):505-14.

152. World Health Organization. Progress report on the elimination of human onchocerciasis, 2016-2017. Wkly Epidemiol Rec. 2017;92(45):681-94.

153. World Health Organization/African Programme for Onchocerciasis Control Report of the external mid-term evaluation of the African Programme for Onchocerciasis Control. World Health Organization; JAF 16.8. 2010. http:// apps.who.int/iris/handle/10665/275418. Accessed 19 Oct 2018.

154. Akogun OB, Akogun MK, Audu Z. Community-perceived benefits of ivermectin treatment in northeastern Nigeria. Soc Sci Med. 2000;50(10): 1451-6.

155. Brieger WR, Otusanya SA, Oke GA, Oshiname FO, Adeniyi JD. Factors associated with coverage in community-directed treatment with ivermectin for onchocerciasis control in Oyo State, Nigeria. Tropical Med Int Health. 2002;7(1):11-8.

156. Haselow NJ, Akame J, Evini C, Akongo S. Programmatic and communication issues in relation to serious adverse events following ivermectin treatment in areas co-endemic for onchocerciasis and loiasis. Filaria J. 2003;2(1):S10.

157. Nuwaha F, Okware J, Ndyomugyenyi R. Predictors of compliance with community-directed ivermectin treatment in Uganda: quantitative results. Tropical Med Int Health. 2005;10(7):659-67.

158. Semiyaga NB, Lalobo O, Ndyomugyenyi R. Refusal to take ivermectin: the associated risk factors in Hoima district, Uganda. Ann Trop Med Parasitol. 2005;99(2):165-72.

159. Anosike JC, Dozie IN, Ameh Gl, Ukaga CN, Nwoke BE, Nzechukwu CT, et al. The varied beneficial effects of ivermectin (Mectizan ${ }^{\oplus}$ ) treatment, as observed within onchocerciasis foci in south-eastern Nigeria. Ann Trop Med Parasitol. 2007;101(7):593-600.

160. Brieger WR, Okeibunor JC, Abiose AO, Ndyomugyenyi R, Kisoka W, Wanji S, et al. Feasibility of measuring compliance to annual ivermectin treatment in the African Programme for Onchocerciasis Control. Tropical Med Int Health. 2007;12(2):260-8.

161. Dimomfu BL, Lubeji DK, Noma M, Sékétéli A, Boussinesq M. African Programme for Onchocerciasis Control (APOC): sociological study in three foci of central Africa before the implementation of treatments with ivermectin (Mectizan ${ }^{\circledast}$ ). Trans R Soc Trop Med Hyg. 2007;101(7):674-9.

162. Ndyomugyenyi R, Byamungu A, Korugyendo R. Perceptions on onchocerciasis and ivermectin treatment in rural communities in Uganda: implications for long-term compliance. Int Health. 2009;1(2):163-8.

163. Yirga D, Deribe $K$, Woldemichael K, Wondafrash M, Kassahun W. Factors associated with compliance with community directed treatment with ivermectin for onchocerciasis control in Southwestern Ethiopia. Parasit Vectors. 2010;3(1):48

164. Okeibunor JC, Amuyunzu-Nyamongo M, Onyeneho NG, Tchounkeu YF, Manianga C, Kabali AT, Leak S. Where would I be without ivermectin? Capturing the benefits of community-directed treatment with ivermectin in Africa. Tropical Med Int Health. 2011;16(5):608-21. 
165. Endale A, Erko B, Weldegebreal F, Legesse M. Predictors of compliance with community-directed treatment with ivermectin for onchocerciasis control in Kabo area, southwestern Ethiopia. Parasit Vectors. 2015;8(1):99.

166. Wanji S, Kengne-Ouafo JA, Esum ME, Chounna PW, Adzemye BF, Eyong JE et al. Relationship between oral declaration on adherence to ivermectin treatment and parasitological indicators of onchocerciasis in an area of persistent transmission despite a decade of mass drug administration in Cameroon. Parasit Vectors. 2015;8(1):667

167. Kamga GR, Dissak-Delon FN, Nana-Djeunga HC, Biholong BD, MbighaGhogomu S, Souopgui J, et al. Still mesoendemic onchocerciasis in two Cameroonian community-directed treatment with ivermectin projects despite more than 15 years of mass treatment. Parasit Vectors. 2016;9(1):581.

168. Senyonjo L, Oye J, Bakajika D, Biholong B, Tekle A, Boakye D, et al. Factors associated with ivermectin non-compliance and its potential role in sustaining onchocerca volvulus transmission in the West Region of Cameroon. PLoS Negl Trop Dis. 2016;10(8):e0004905.

169. Njim T, Aminde LN. An appraisal of the neglected tropical diseases control program in Cameroon: the case of the national program against onchocerciasis. BMC Public Health. 2017;17(1):103.

170. Turner HC, Walker M, Churcher TS, Osei-Atweneboana MY, Biritwum NK, Hopkins A, et al. Reaching the London Declaration on Neglected Tropical Diseases goals for onchocerciasis: an economic evaluation of increasing the frequency of ivermectin treatment in Africa. Clin Infect Dis. 2014;59(7): 923-32.

171. Kolaczinski JH, Kabatereine NB, Onapa AW, Ndyomugyenyi R, Kakembo AS, Brooker S. Neglected tropical diseases in Uganda: the prospect and challenge of integrated control. Trends Parasitol. 2007;23(10):485-93.

172. Kabatereine NB, Malecela M, Lado M, Zaramba S, Amiel O, Kolaczinski JH. How to (or not to) integrate vertical programmes for the control of major neglected tropical diseases in sub-Saharan Africa. PLoS Negl Trop Dis. 2010; 4(6):e755.

173. World Health Organization/African Programme for Onchocerciasis Control. The World Health Organization African Programme for Onchocerciasis Control Final Evaluation Report. African Programme for Onchocerciasis Control; 2015. https://www.who.int/about/evaluation/jaf21-apoc-finalreport15-v5.pdf. Accessed 30 Jan 2019.

174. Hopkins AD. Challenges for the integration of mass drug administrations against multiple neglected tropical diseases'. Ann Trop Med Parasitol. 2009; 103(sup1):23-31

175. Hopkins DR, Richards FO, Katabarwa M. Whither onchocerciasis control in Africa? Am J Trop Med Hyg. 2005;72(1):1-2.

176. Rakers L, Emukah E, Onyenama J, Amah G, Ukairo N, Enyinnaya U, et al. Sustainability of ivermectin distribution programmes. Lancet. 2009; 374(9692):785-6.

177. Katabarwa MN, Lakwo T, Habomugisha P, Unnasch TR, Garms R, HudsonDavis $L$, et al. After 70 years of fighting an age-old scourge, onchocerciasis in Uganda, the end is in sight. Int Health. 2018;10(suppl 1):i79-88.

178. Royal Society of Tropical Medicine and Hygiene. Where are we in the fight against onchocerciasis or river blindness? https://rstmh.org/blog/2018/feb/ 20/where-are-we-fight-against-onchocerciasis-or-\%E2\%80\%9Criverblindness\%E2\%80\%9D. Accessed 12 Oct 2018.

179. IAPB Vision Atlas. Onchocerciasis - now on target for eradication thanks to Mectizan. http://atlas.iapb.org/vision-trends/onchocerciasis/. Accessed 23 Oct 2018.

180. Mathauer I, Imhoff I. Health worker motivation in Africa: the role of nonfinancial incentives and human resource management tools. Hum Resour Health. 2006;4(1):24.

181. Dembélé M, Bamani S, Dembélé R, Traoré MO, Goita S, Traoré MN, et al. Implementing preventive chemotherapy through an integrated national neglected tropical disease control program in Mali. PLoS Negl Trop Dis. 2012;6(3):e1574.

182. Neglected Tropical Diseases Support Center. Motivating Community Drug Distributors Fight Against NTDs. https://www.ntdsupport.org/corntd/blog/motivating-community-drug-distributors-fight-against-ntds. Accessed 22 Oct 2018.

183. Takasugi T, Lee AC. Why do community health workers volunteer? A qualitative study in Kenya. Public Health. 2012;126(10):839-45.

184. Njomo DW, Amuyunzu-Nyamongo M, Magambo JK, Ngure PK, Njenga SM Factors associated with the motivation of community drug distributors in the Lymphatic Filariasis Elimination Programme in Kenya. South Afr J Epidemiol Infect. 2012;27(2):66-70.
185. da-Costa Vroom FB, Aryeetey R, Boateng R, Anto F, Aikins M, Gyapong M, et al. Data reporting constraints for the lymphatic filariasis mass drug administration activities in two districts in Ghana: A qualitative study. SAGE Open Med. 2015;3:2050312115594083.

186. Brito M, Paulo R, Van-Dunem P, Martins A, Unnasch TR, Novak RJ, et al. Rapid integrated clinical survey to determine prevalence and co-distribution patterns of lymphatic filariasis and onchocerciasis in a Loa loa co-endemic area: the Angolan experience. Parasite Epidemiol Control. 2017;2(3):71-84.

187. Kelly-Hope LA, Blundell HJ, Macfarlane CL, Molyneux DH. Innovative Surveillance Strategies to Support the Elimination of Filariasis in Africa. Trends Parasitol. 2018.

188. World Health Organization. Guide for decision making and implementation of vector control as alternative treatment strategies for elimination of onchocerciasis. WHO/MG/15.22. World Health Organization. 2015. http:// www.who.int/apoc/ATS_Report_Annex2_Guide_on_Vector_Control_ATS. pdf. Accessed 14 Nov 2018.

189. Rebollo MP, Zoure H, Ogoussan K, Sodahlon Y, Ottesen EA, Cantey PT. Onchocerciasis: shifting the target from control to elimination requires a new first-step-elimination mapping. Int Health. 2018;10(suppl 1):i14-9.

190. Steel C, Golden A, Stevens E, Yokobe L, Domingo GJ, de los Santos T, et al. Rapid point-of-contact tool for mapping and integrated surveillance of Wuchereria bancrofti and Onchocerca volvulus infection. Clin Vaccine Immunol. 2015;22(8):896-901.

191. Gass KM. Rethinking the serological threshold for onchocerciasis elimination. PLoS Negl Trop Dis. 2018;12(3):e0006249.

192. Golden A, Stevens EJ, Yokobe L, Faulx D, Kalnoky M, Peck R, et al. A recombinant positive control for serology diagnostic tests supporting elimination of Onchocerca volvulus. PLoS Negl Trop Dis. 2016;10(1): e0004292.

193. World Health Organization. Report of the Second Meeting of the WHO Onchocerciasis Technical Advisory Subgroup. Geneva, Switzerland. 12-14 February 2018. World Health Organization; 2018. https://apps.who.int/iris/ bitstream/handle/10665/277238/WHO-CDS-NTD-PCT-2018.11-eng.pdf?ua=1. Accessed 30 Jan 2019.

194. Baker MC, Krotki K, Sankara DP, Trofimovich L, Zoerhoff KL, Courtney L, et al. Measuring treatment coverage for neglected tropical disease control programs: analysis of a survey design. Am J Epidemiol. 2013;178(2):268-75

195. Meribo K, Kebede B, Feleke SM, Mengistu B, Mulugeta A, Sileshi M, et al. Review of Ethiopian onchocerciasis elimination programme. Ethiop Med J. 2017:55(Suppl 1):55.

196. Rapid Monitoring of Preventive Chemotherapy Coverage in Neglected Tropical Disease Programmes Supervisor's Coverage Tool. World Health Organization: World Health Organization; 2016. https://www.ntdenvision. org/sites/default/files/docs/supervisors_coverage_tool_-_guidelines_for_ implementation_29nov2016_clean.pdf. Accessed 20 Nov 2018

197. Bof JC, Mpunga D, Soa EN, Ntumba F, Bakajika D, Murdoch ME, et al. Onchocerciasis in the Democratic Republic of Congo: Survey of knowledge, attitude and perception in Bandundu province. J Infect Public Health. 2017; 10(5):600-7.

198. Awadzi K, Opoku NO, Attah SK, Lazdins-Helds J, Kuesel AC. A randomized, singleascending-dose, ivermectin-controlled, double-blind study of moxidectin in Onchocerca volvulus infection. PLoS Negl Trop Dis. 2014;8(6):e2953.

199. Turner HC, Walker M, Attah SK, Opoku NO, Awadzi K, Kuesel AC, et al. The potential impact of moxidectin on onchocerciasis elimination in Africa: an economic evaluation based on the Phase II clinical trial data. Parasit Vectors. 2015;8(1):167.

200. Opoku NO, Bakajika DK, Kanza EM, Howard H, Mambandu GL, Nyathirombo A, et al. Single dose moxidectin versus ivermectin for Onchocerca volvulus infection in Ghana, Liberia, and the Democratic Republic of the Congo: a randomised, controlled, double-blind phase 3 trial. Lancet. 2018;392(10154): 1207-16.

201. The U.S. Food and Drug Administration. Highlights of Prescribing Information. https://www.accessdata.fda.gov/drugsatfda_docs/label/2018/ 210867lbl.pdf. Accessed 16 Nov 2018.

202. World Health Organization. First new treatment for river blindness approved by U.S. FDA in 20 years. http://www.who.int/tdr/news/2018/moxidectinapproved-as-treatment-for-river-blindness/en/. Accessed 16 Nov 2018.

203. PR Newswire. U.S. FDA Approves Moxidectin For The Treatment Of River Blindness. https://www.prnewswire.com/news-releases/us-fda-approvesmoxidectin-for-the-treatment-of-river-blindness-300666114.html. Accessed 16 Nov 2018. 
204. MPR. FDA Approves New Treatment for Onchocerciasis. https://www.empr. com/news/moxidectin-oral-river-blindness-onchocerciasis-onchocercavolvulus/article/773465/. Accessed 16 Nov 2018.

205. Boussinesq M. A new powerful drug to combat river blindness. Lancet. 2018;392:1170.

206. Walker M, Specht S, Churcher TS, Hoerauf A, Taylor MJ, Basáñez MG. Therapeutic efficacy and macrofilaricidal activity of doxycycline for the treatment of river blindness. Clin Infect Dis. 2014;60(8):1199-207.

207. Cheke RA. Factors affecting onchocerciasis transmission: lessons for infection control. Expert Rev Anti-Infect Ther. 2017;15(4):377-86.

208. Davies JB. Sixty years of onchocerciasis vector control: a chronological summary with comments on eradication, reinvasion, and insecticide resistance. Annu Rev Entomol. 1994;39(1):23-45.

209. The Schools and Health. Carter Centre focus on River Blindness moves to elimination. http://www.schoolsandhealth.org/News/Pages/ Carter\%20Centre\%20focus\%20on\%20River\%20Blindness\%20moves \%20to\%20elimination.aspx. Accessed 12 Oct 2018.

Ready to submit your research? Choose BMC and benefit from:

- fast, convenient online submission

- thorough peer review by experienced researchers in your field

- rapid publication on acceptance

- support for research data, including large and complex data types

- gold Open Access which fosters wider collaboration and increased citations

- maximum visibility for your research: over $100 \mathrm{M}$ website views per year

At BMC, research is always in progress.

Learn more biomedcentral.com/submissions 